\title{
Color and Brightness Tuning in Heteronuclear Lanthanide Terephthalate Coordination Polymers
}

\author{
Victor Haquin, ${ }^{[a, b]}$ Mael Etienne, ${ }^{[a, b]}$ Carole Daiguebonne, ${ }^{[a, b]}$ \\ Stéphane Freslon, ${ }^{[a, b]}$ Guillaume Calvez, ${ }^{[a, b]}$ Kevin Bernot, ${ }^{[a, b]}$ \\ Laurent Le Pollès, ${ }^{*[a, c]}$ Sharon E. Ashbrook, ${ }^{[d]}$ Martin R. Mitchell, ${ }^{[d]}$ \\ Jean-Claude Bünzli, $*\left[e,[]\right.$ Svetlana V. Eliseeva, ${ }^{[e]}$ and \\ Olivier Guillou*[a,b]
}

Keywords: Lanthanides / Coordination polymers / Luminescence / Structure elucidation

Heteronuclear lanthanide terephthalate coordination polymers with the general chemical formula $\left[\operatorname{Ln}_{2-2 x} \operatorname{Ln}_{2 x}(b d c)_{3^{-}}\right.$ $\left.\left(\mathrm{H}_{2} \mathrm{O}\right)_{4}\right]_{\infty}$, for which bdc $^{2-}$ symbolizes benzene-1,4-dicarboxylate (or terephthalate) and Ln and $\mathrm{Ln}^{\prime}$ represent trivalent rare earth ions, were synthesized and structurally characterized. Analysis of the Y/Lu compounds by ${ }^{89} \mathrm{Y}$ and ${ }^{13} \mathrm{C}$ solid-state NMR spectroscopy was carried out, and the results support the hypothesis of randomly distributed lanthanide ions. The spectroscopic and colorimetric properties of this family of compounds were investigated in detail. The resulting data demonstrate that this series of compounds presents highly tunable luminescence properties and clearly indicate that intermetallic deactivation processes play an important role in the emission mechanism. Playing with intermetallic distances allows one to tune the color and the brightness of the lanthanide emission in these coordination polymers.

\section{Introduction}

For more than a decade, lanthanide-based coordination polymers have attracted great attention, because of their fascinating topologies coupled with their potential applications in gas storage, ${ }^{[1-8]}$ catalysis, ${ }^{[9]}$ separation, ${ }^{[10]}$ luminescence, ${ }^{[11-16]}$ and molecular magnetism. ${ }^{[17-19]}$ Because lanthanide ions are hard Pearson acids, ${ }^{[20,21]}$ ligands that exhibit donor oxygen atoms have been extensively studied. ${ }^{[22,23]}$ Among these ligands, special attention has been paid to benzene polycarboxylate ligands, ${ }^{[24]}$ which are chemically and thermally stable, present a structuring effect through

[a] Université européenne de Bretagne,

5 Boulevard Laënnec, 35000 Rennes, France

[b] INSA, UMR 6226" "Institut des Sciences Chimiques de Rennes",

35708 Rennes, France

Fax: +33-2-23238785

Olivier.guillou@insa-rennes.fr

Homepage: http://www.insa-rennes.fr/themes-recherche/ laboratoires.html

[c] ENSCR, UMR 6226 "Institut des Sciences Chimiques de Rennes",

35708 Rennes, France

E-mail: laurent.le-polles@ensc-rennes.fr

[d] School of Chemistry, University of St. Andrews, North Haugh, St Andrews, KY16 9ST, UK

[e] École Polytechnique Fédérale de Lausanne, ISIC, BCH 1402, 1015 Lausanne, Switzerland E-mail: jean-claude.bunzli@epfl.ch

[f] Department of Materials Chemistry, Korea University, Sejong Campus,

Jochiwon-eup, Sejong-si 339-700, Republic of Korea

Supporting information for this article is available on the WWW under http://dx.doi.org/10.1002/ejic.201300381. $\pi$ stacking and hydrogen bonds, and possess carboxylate functional groups that allow one to expect great structural diversity as a result of their numerous coordination modes. For these reasons, numerous lanthanide-containing coordination polymers involving such ligands have been reported. Great attention has particularly been devoted to lanthanide terephthalate coordination polymers, ${ }^{[25-30]}$ because the terephthalate rodlike ligand is nontoxic and commercially available at low cost (see Scheme 1).

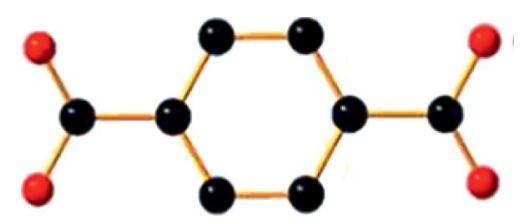

Scheme 1. Benzene-1,4-dicarboxylate ( $\mathrm{bdc}^{2-}$ ) or terephthalate.

Lanthanide terephthalate coordination polymers with the general chemical formula $\left[\mathrm{Ln}_{2}(\mathrm{bdc})_{3}\left(\mathrm{H}_{2} \mathrm{O}\right)_{4}\right]_{\infty}$, for which $\mathrm{Ln}=\mathrm{La}-\mathrm{Tm}$ (except Pm) plus $\mathrm{Y}^{[26]}$ are of particular interest, because they can be almost quantitatively obtained as precipitated microcrystalline powders by mixing aqueous solutions of lanthanide chloride and sodium terephthalate at room temperature. Moreover, this crystalline phase (see Figure 1) is very stable, and it has been proven that heteronuclear compounds with the general chemical formula $\left[\left(\sum_{i=1}^{13} \mathrm{Ln}_{x_{\mathrm{i}}}^{i}\right)\left(\mathrm{C}_{8} \mathrm{H}_{4} \mathrm{O}_{4}\right)_{3}\left(\mathrm{H}_{2} \mathrm{O}\right)_{4}\right]_{\infty}$, with $\sum_{i=1}^{13} x_{i}=2^{[56]}$ and for 
which $\mathrm{Ln}^{i}$ symbolizes one of the trivalent lanthanide ions between $\mathrm{La}$ and $\mathrm{Tm}$ (except Pm) or Y, exhibit the same crystal structure as that exhibited by homologous homonuclear compounds. ${ }^{[31,32]}$ They also present highly tunable luminescence properties. ${ }^{[31]}$ Furthermore, their quite intense luminescence has made them good candidates for luminescent tagging in the fight against counterfeiting. ${ }^{[3,34]}$ However, these smart luminescence properties have not been studied in detail, and up to date, only a few reported works deal with heteronuclear lanthanide containing coordination polymers. ${ }^{[29,31,32,35-37]}$ In this paper, the spectroscopic and colorimetric properties of heteronuclear lanthanide terephthalate coordination polymers are deciphered with the aim of gaining easy tuning of the color and brightness of the lanthanide-centered emission by adjusting the intermetallic distances.

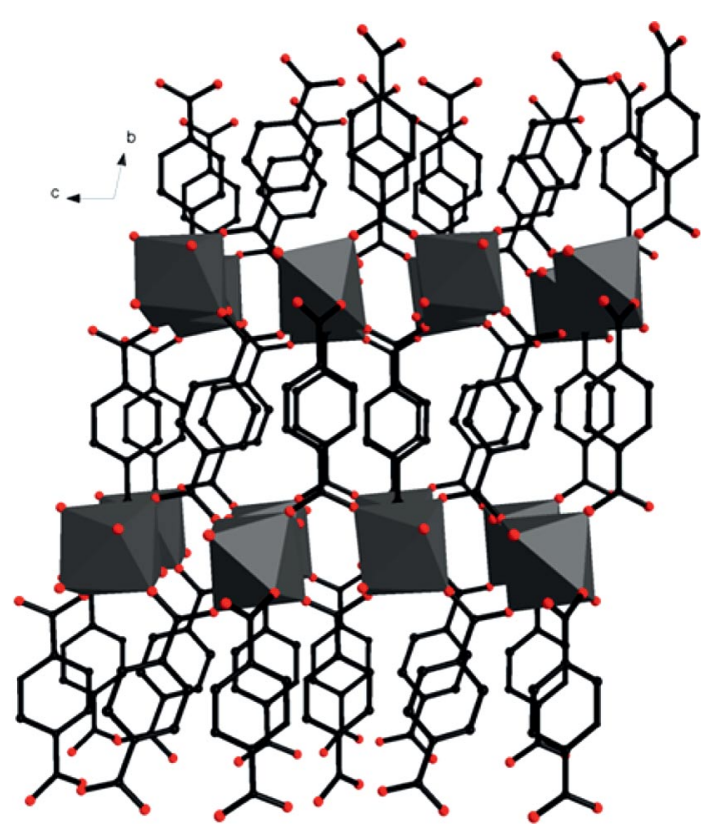

Figure 1. Perspective view along the $\vec{a}$ axis of $\left[\mathrm{Tb}_{2}(\mathrm{bdc})_{3^{-}}\right.$ $\left.\left(\mathrm{H}_{2} \mathrm{O}\right)_{4}\right]_{\infty} .^{[25]}$

\section{Results and Discussion}

All the heterometallic lanthanide terephthalate coordination polymers studied in this paper are isostructural with the previously described $\left[\mathrm{Tb}_{2}(\mathrm{bdc})_{3}\left(\mathrm{H}_{2} \mathrm{O}\right)_{4}\right]_{\infty}$ compound. ${ }^{[25]}$ This compound crystallizes in the triclinic system, space group $P \overline{1}$ (no. 2) with $a=6.1420$ (2) $\AA, b=10.0694(2) \AA, c$ $=10.0956(3) \AA, a=102.247(2)^{\circ}, \beta=91.118(1)^{\circ}$, and $\gamma=$ $101.518(2)^{\circ}$. In this crystal structure, there is only one crystallographically independent $\mathrm{Tb}^{3+}$ ion that occupies a $2 \mathrm{i}$ Wyckoff position. This is in agreement with previously reported luminescence studies in which only one metal ion environment with a pseudo $C_{4}$ symmetry was observed in the homonuclear $\left[\mathrm{Eu}_{2}(\mathrm{bdc})_{3}\left(\mathrm{H}_{2} \mathrm{O}\right)_{4}\right]_{\infty}{ }^{[26]}$ compound. Powder $\mathrm{X}$-ray diffraction studies showed that in these compounds there is no long-range order or segregation. ${ }^{[31]}$ Recent papers proved that ${ }^{89} \mathrm{Y}$ NMR spectroscopy is a useful probe for local ordering in solid-state compounds. ${ }^{[38-41]}$ Consequently, we performed ${ }^{13} \mathrm{C}$ CPMAS and ${ }^{89} \mathrm{Y}$ MAS NMR experiments on a series of $\left[\mathrm{Ln}_{2-2 x} \mathrm{Ln}_{2 x}^{\prime}(\mathrm{bdc})_{3}\left(\mathrm{H}_{2} \mathrm{O}\right)_{4}\right]_{\infty} \mathrm{com}-$ pounds with various yttrium and lanthanum contents. Nonmagnetic lanthanides were chosen to achieve high-resolu-

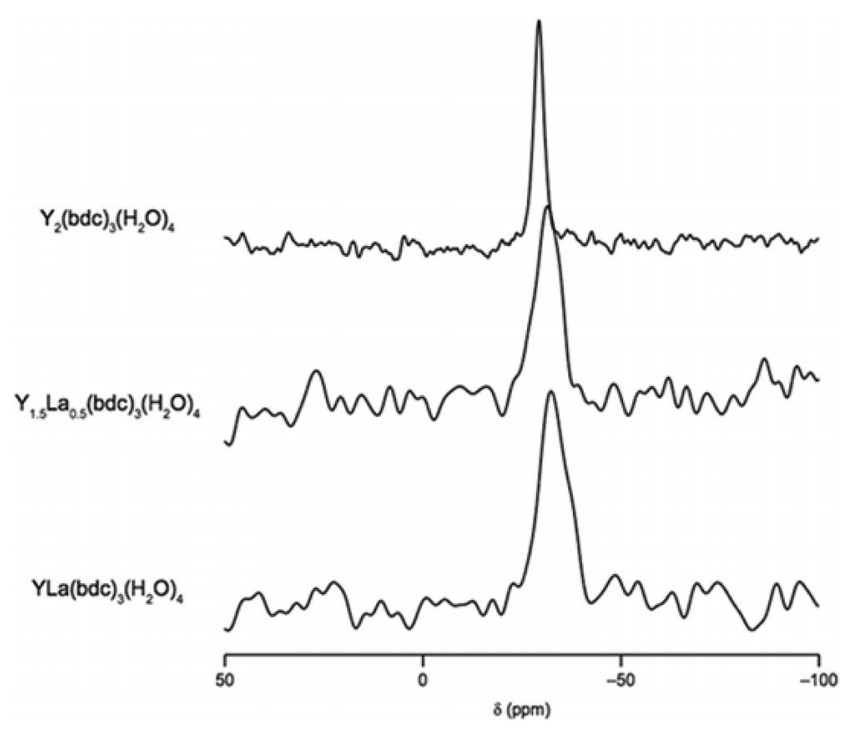

Figure 2. ${ }^{89} \mathrm{Y}$ MAS NMR spectra recorded for a series of $\left[\mathrm{Y}_{2-2 x} \mathrm{La}_{2 x}(\mathrm{bdc})_{3}\left(\mathrm{H}_{2} \mathrm{O}\right)_{4}\right]_{\infty}$ compounds.

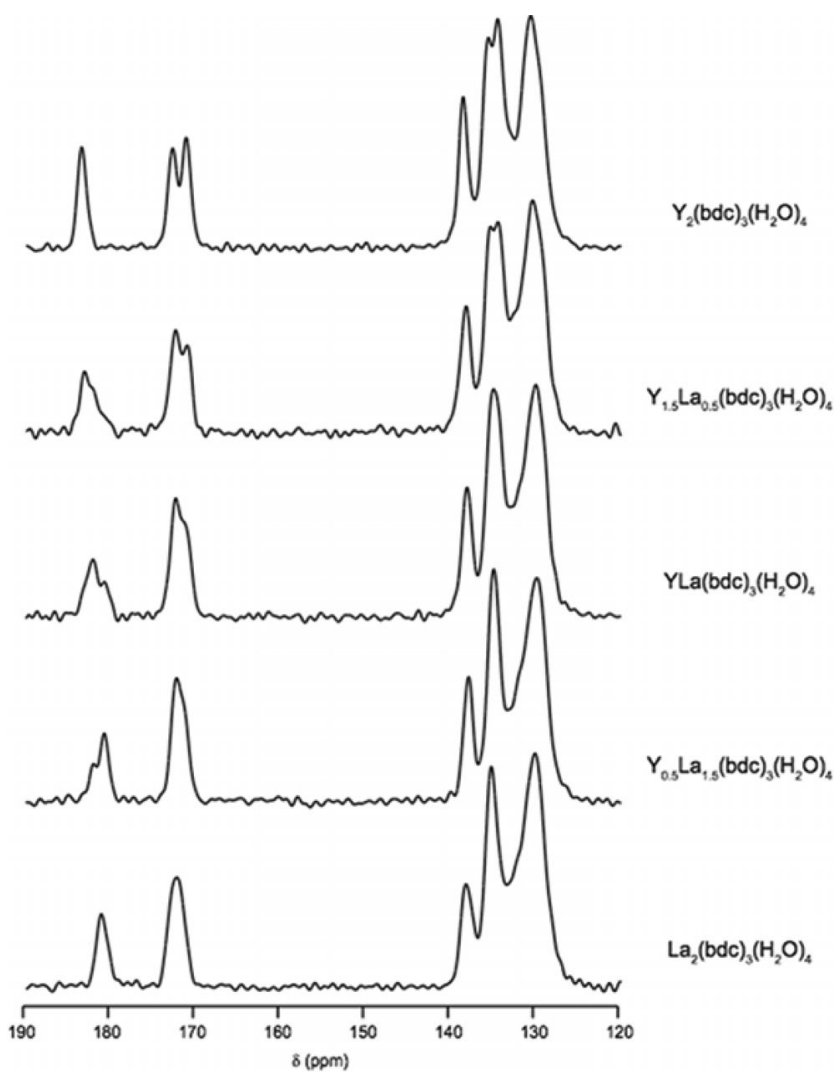

Figure $3 .{ }^{13} \mathrm{C}$ CPMAS spectra recorded for $\left[\mathrm{Y}_{2}(\mathrm{bdc})_{3}\left(\mathrm{H}_{2} \mathrm{O}\right)_{4}\right]_{\infty},\left[\mathrm{La}_{2}\right.$ $\left.(\mathrm{bdc})_{3}\left(\mathrm{H}_{2} \mathrm{O}\right)_{4}\right]_{\infty}, \quad\left[\mathrm{Y}_{1.5} \mathrm{La}_{0.5}(\mathrm{bdc})_{3}\left(\mathrm{H}_{2} \mathrm{O}\right)_{4}\right]_{\infty}$, and $\left[\mathrm{Y}_{0.5} \mathrm{La}_{1.5}(\mathrm{bdc})_{3}\right.$ $\left.\left(\mathrm{H}_{2} \mathrm{O}\right)_{4}\right]_{\infty}$. Aromatic carbon atoms are in the range $120-140 \mathrm{ppm}$ and carboxylate carbon atoms are in the range $170-190 \mathrm{ppm}$. 
tion solid-state NMR experiments. These measurements (Figures 2 and 3) show no evidence of local ordering and support the interpretation of randomly distributed yttrium and lanthanum atoms.

Figure 2 clearly shows that regardless of the lanthanum doping rate, the ${ }^{89} \mathrm{Y}$ NMR signal remains almost identical. This indicates that the local environment of the $\mathrm{Y}^{3+}$ ions remains unchanged. ${ }^{13} \mathrm{C}$ CPMAS NMR experiments (Figure 3) gave the same information with respect to the local distribution of the lanthanide ions; the NMR spectra of Y/ La mixed compounds cannot be described as the superimposition of the pure yttrium and lanthanum compounds.
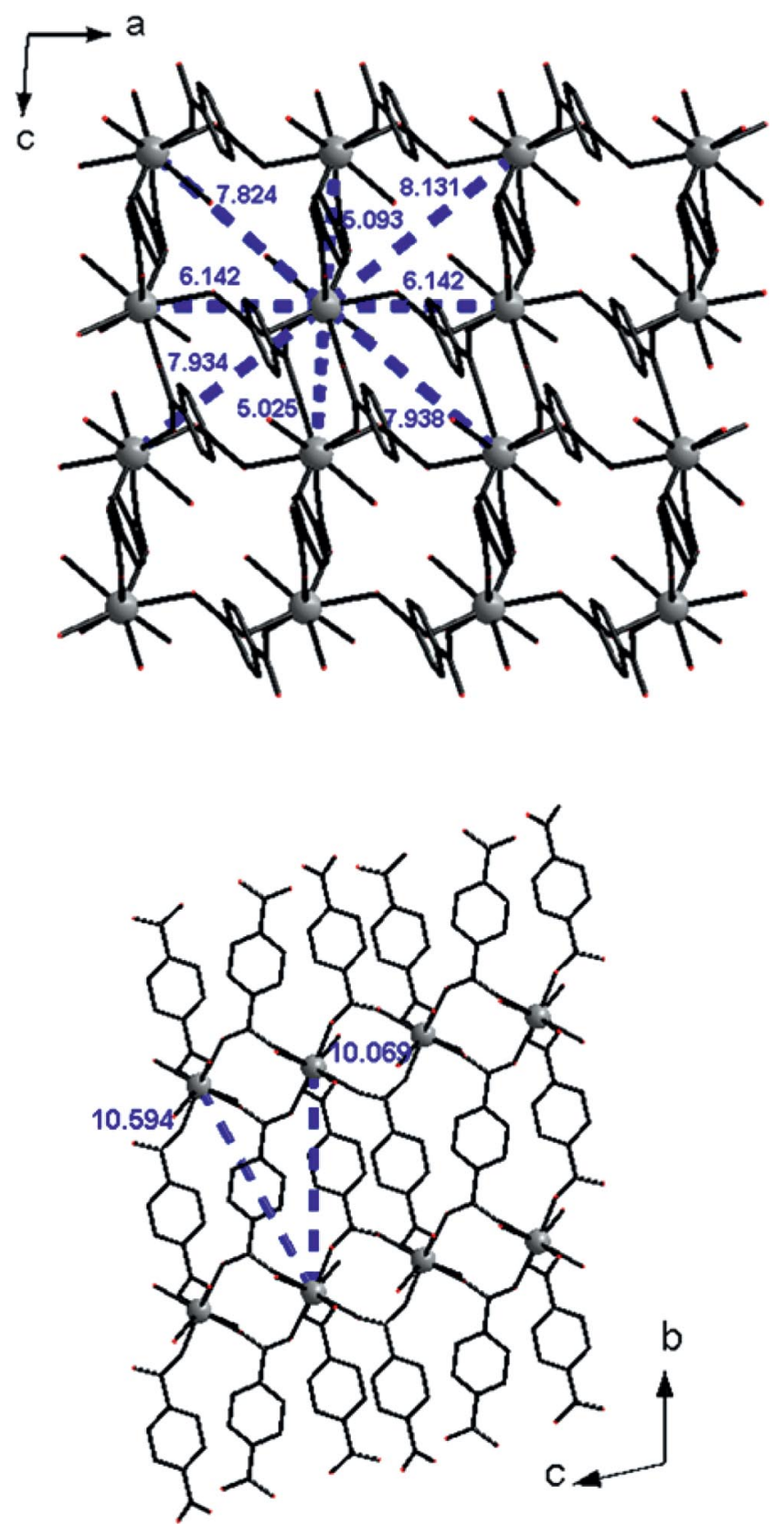

Figure 4. Projection view along the $\vec{b}$ (top) and $\vec{a}$ (bottom) axes of $\left[\mathrm{Tb}_{2}(\mathrm{bdc})_{3}\left(\mathrm{H}_{2} \mathrm{O}\right)_{4}\right]_{\infty}$. The shortest intermetallic distances are reported.
Therefore, there is no NMR evidence for local ordering of rare earth ions. On the basis of these experiments, it can be assumed that, in these heteronuclear compounds, the metal ions are perfectly randomly distributed over the different metallic sites of the crystal structure.

To evaluate the mean distance between the lanthanide ions in the crystal structure of the homonuclear $\mathrm{Tb}^{3+}$-containing compound, we estimated the mean volume occupied by a lanthanide ion as being the cell volume divided by the number of lanthanide ions per unit cell. ${ }^{[42]}$ In the present case, the mean volume is roughly $\tilde{v}=298 \AA^{3}$ per metallic ion. This corresponds to the volume of a sphere with a radius of $4.15 \AA\left[r=\left(\frac{3 \tilde{v}}{4 \pi}\right)^{1 / 3}\right]$. With this rather rough model, the mean distance between two lanthanide ions is thus 8.3 ̊. A finer analysis shows that this crystal structure can be described as planes that spread parallel to the $(\vec{a}, \vec{c})$ plane and that lie more than $10 \AA$ apart from each other (see Figure 4). Therefore, a given $\mathrm{Tb}^{3+}$ ion is surrounded by eight other $\mathrm{Tb}^{3+}$ ions at distances between 5.0 and $8.1 \AA$ and located in the same plane.

\section{Homonuclear Compounds}

When exposed to UV radiation, some of the homonuclear compounds emitted visible light (see Figure 5): $\left[\mathrm{Sm}_{2}(\mathrm{bdc})_{3}\left(\mathrm{H}_{2} \mathrm{O}\right)_{4}\right]_{\infty}$ (purple luminescence), $\left[\mathrm{Eu}_{2}(\mathrm{bdc})_{3^{-}}\right.$ $\left.\left(\mathrm{H}_{2} \mathrm{O}\right)_{4}\right]_{\infty}$ (red luminescence), $\left[\mathrm{Tb}_{2}(\mathrm{bdc})_{3}\left(\mathrm{H}_{2} \mathrm{O}\right)_{4}\right]_{\infty}$ (green luminescence), and $\left[\mathrm{Dy}_{2}(\mathrm{bdc})_{3}\left(\mathrm{H}_{2} \mathrm{O}\right)_{4}\right]_{\infty}$ (yellow luminescence). The excitation spectra present broad bands from bdc $^{2-}$ below $320 \mathrm{~nm}$, which confirms the sensitization of the $\mathrm{Ln}^{3+}$ luminescence by the ligand (Figure S1, Supporting Information). These spectra also show that $312 \mathrm{~nm}$ is an efficient excitation wavelength for these compounds. ${ }^{[26]}$ This is an interesting result as far as industrial applications are concerned, because this is a cheap commercially available irradiation wavelength. Therefore, the excitation wavelength was chosen as $312 \mathrm{~nm}$ in the following study.

The emission spectrum of the Sm-based compound exhibits typical $\mathrm{Sm}^{3+}{ }^{4} \mathrm{G}_{5 / 2} \rightarrow{ }^{6} \mathrm{H}_{J}(J=5 / 2-11 / 2)$ transitions and is dominated by the ${ }^{4} \mathrm{G}_{5 / 2} \rightarrow{ }^{6} \mathrm{H}_{7 / 2}$ and ${ }^{4} \mathrm{G}_{5 / 2} \rightarrow{ }^{6} \mathrm{H}_{9 / 2}$ transitions at 598 and $644 \mathrm{~nm}$, respectively. The spectrum of the Eu-based compound displays typical $\mathrm{Eu}^{3+}{ }^{5} \mathrm{D}_{0} \rightarrow{ }^{7} \mathrm{~F}_{J}(J=$ $0-4)$ transitions and is dominated by the ${ }^{5} \mathrm{D}_{0} \rightarrow{ }^{7} \mathrm{~F}_{2}$ transition at $615 \mathrm{~nm}$. The spectrum of the Tb-based compound features the characteristic $\mathrm{Tb}^{3+}{ }^{5} \mathrm{D}_{4} \rightarrow{ }^{7} \mathrm{~F}_{J}(J=0-6)$ transitions and is dominated by the ${ }^{5} \mathrm{D}_{4} \rightarrow{ }^{7} \mathrm{~F}_{5}$ transition at $545 \mathrm{~nm}$. Finally, emission from the Dy-based compound arises from the $\mathrm{Dy}^{3+}{ }^{4} \mathrm{~F}_{9 / 2} \rightarrow{ }^{6} \mathrm{H}_{J}(J=15 / 2-9 / 2)$ transitions and is dominated by the ${ }^{4} \mathrm{~F}_{9 / 2} \rightarrow{ }^{6} \mathrm{H}_{13 / 2}$ transition at $571 \mathrm{~nm}$. Notably, the Gd-based coordination polymer only displays ligand emission. The luminescence quantum yields $(\Phi)$, lifetimes $\left(\tau_{\mathrm{obs}}\right)$, and colorimetric parameters for these compounds are listed in Table 1. For all of them, the luminescence decay profiles are monoexponential.

The weak luminescence intensities of the Sm- and Dybased compounds can be related to their small energy gaps $^{[43]}$ that favor nonradiative deactivation. Therefore, we 

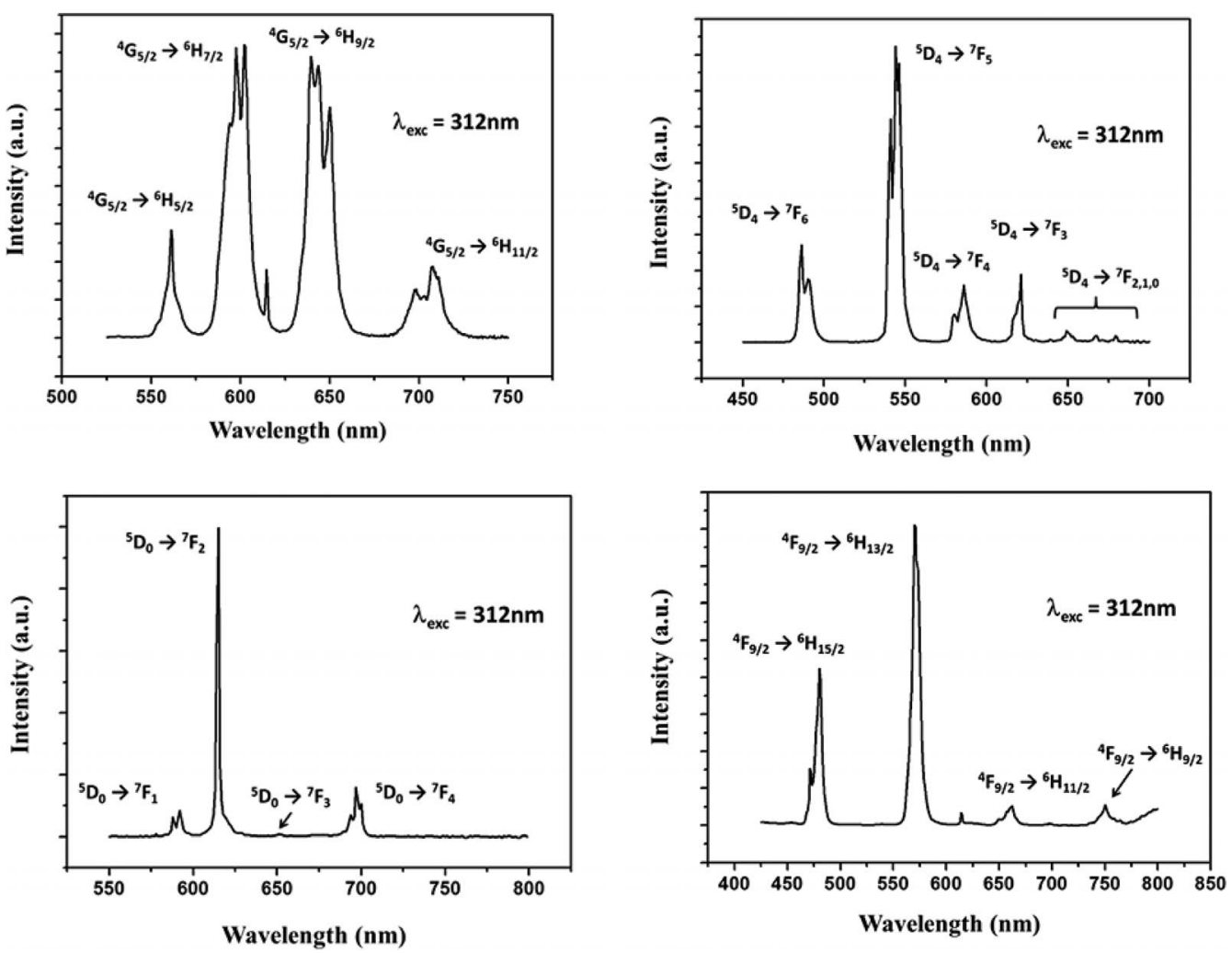

Figure 5. Emission spectra of $\left[\mathrm{Sm}_{2}(\mathrm{bdc})_{3}\left(\mathrm{H}_{2} \mathrm{O}\right)_{4}\right]_{\infty}$ (top left), $\left[\mathrm{Eu}_{2}(\mathrm{bdc})_{3}\left(\mathrm{H}_{2} \mathrm{O}\right)_{4}\right]_{\infty}$ (bottom left), $\left[\mathrm{Tb}_{2}(\mathrm{bdc})_{3}\left(\mathrm{H}_{2} \mathrm{O}\right)_{4}\right]_{\infty}$ (top right), and $\left[\mathrm{Dy}_{2}(\mathrm{bdc})_{3}\left(\mathrm{H}_{2} \mathrm{O}\right)_{4}\right]_{\infty}$ (bottom right).

Table 1. Spectroscopic and colorimetric data for homonuclear $\left[\mathrm{Ln}_{2}(\mathrm{bdc})_{3}\left(\mathrm{H}_{2} \mathrm{O}\right)_{4}\right]_{\infty}$ compounds

\begin{tabular}{llllll}
\hline Compound & $\Phi(\%)$ & $\tau_{\text {obs }}(\mathrm{ms})$ & $x$ & $y$ & $\begin{array}{l}\text { Luminance }^{[\mathrm{a}]} \\
\left(\mathrm{Cd} \mathrm{m}^{-2}\right)\end{array}$ \\
\hline$\left[\mathrm{Sm}_{2}(\mathrm{bdc})_{3}\left(\mathrm{H}_{2} \mathrm{O}\right)_{4}\right]_{\infty}$ & $0.08(1)$ & $0.0021(2)$ & $0.43(1)$ & $0.23(1)$ & $0.2(1)$ \\
{$\left[\mathrm{Eu}_{2}(\mathrm{bdc})_{3}\left(\mathrm{H}_{2} \mathrm{O}\right)_{4}\right]_{\infty}$} & $13.9(14)$ & $0.40(4)$ & $0.66(1)$ & $0.34(1)$ & $10.8(5)$ \\
{$\left[\mathrm{Gd}_{2}(\mathrm{bdc})_{3}\left(\mathrm{H}_{2} \mathrm{O}\right)_{4}\right]_{\infty}$} & - & - & $0.26(1)$ & $0.28(1)$ & $1.6(1)$ \\
{$\left[\mathrm{Tb}_{2}(\mathrm{bdc})_{3}\left(\mathrm{H}_{2} \mathrm{O}\right)_{4}\right]_{\infty}$} & $45.5(45)$ & $1.10(10)$ & $0.34(1)$ & $0.57(1)$ & $142(2)$ \\
{$\left[\mathrm{Dy}{ }_{2}(\mathrm{bdc})_{3}\left(\mathrm{H}_{2} \mathrm{O}\right)_{4}\right]_{\infty}$} & $0.28(3)$ & $0.0011(1)$ & $0.35(1)$ & $0.32(1)$ & $0.3(1)$ \\
\hline
\end{tabular}

[a] The values represent the luminous flux weighted by the spectral response of the human eye.

focused our attention on the Eu- and Tb-based compounds, which exhibit brighter luminescence.

It is well known that one of the most important processes influencing the luminescence properties of $\mathrm{Ln}^{3+}$ ions in lanthanide-based coordination compound is the intramolecular transfer between (usually) the triplet state of the ligand and the lanthanide receiving level(s). The lowest excited singlet and triplet states were estimated respectively by referring to the wavelength of the UV/Vis absorbance edge ( $320 \mathrm{~nm} \approx 31250 \mathrm{~cm}^{-1}$ ) and to the shortest wavelength phosphorescent band $\left(425 \mathrm{~nm} \approx 23530 \mathrm{~cm}^{-1}\right)$ of the Gd-containing compound (Figures S11 and S12, Supporting Information). ${ }^{[44}{ }^{46]}$ According to Reinhoudt's empirical rules ${ }^{[47]}$ the intersystem crossing process becomes effective when $\Delta E\left({ }^{1} \pi \pi^{*}{ }^{3} \pi \pi^{*}\right)$ is at least $5000 \mathrm{~cm}^{-1}$. In the present case, the gap between the singlet and the triplet excited states $\left(7720 \mathrm{~cm}^{-1}\right)$ is favorable for an efficient intersystem crossing process. The luminescence quantum yields of these two compounds are quite high relative to those of other coordi- nation polymers. This is in agreement with Latva's empirical rules. ${ }^{[43,48]}$ Actually, the lowest excited triplet state of the ligand at $23530 \mathrm{~cm}^{-1}$ is supposed to favor a good ligandto-metal energy-transfer process without significant backtransfer. Colorimetric measurements under UV irradiation $\left(\lambda_{\text {exc }}=312 \mathrm{~nm}\right)$ were also performed for these compounds (see Figure 6). The colorimetric data are listed in Table 1.

It can be noticed from these measurements that, as anticipated, the Tb- and Eu-containing compounds emit much more intensively than the other compounds. The Gd-containing compound emits almost no light, and its color is essentially due to the blue fluorescence of the ligand ( $x=$ $0.216, y=0.182$ ). What is more surprising is that the $\mathrm{Tb}$ containing compound emits very intensively $\left(140 \mathrm{Cd} \mathrm{m}^{-2}\right)$ compared with compounds that exhibit higher luminescence quantum yields. ${ }^{[42]}$ This discrepancy between the luminescence quantum yield and the luminescence intensity can be related to the absorption ability of the compounds. Actually, the luminescence quantum yield is a reflection of 


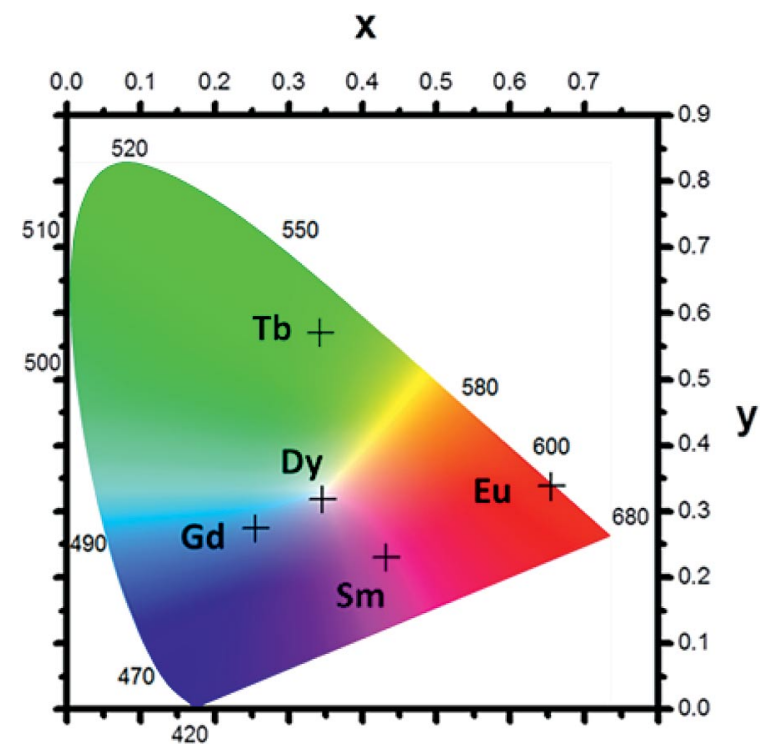

Figure 6. Color coordinates for homonuclear compounds with the general chemical formula $\left[\mathrm{Ln}_{2}(\mathrm{bdc})_{3}\left(\mathrm{H}_{2} \mathrm{O}\right)_{4}\right]_{\infty}$ with $\mathrm{Ln}=\mathrm{Sm}-\mathrm{Dy}$.

the ratio of the number of absorbed photons to the number of emitted photons. Therefore, a highly luminescent compound must present both an important absorption crosssection and a large luminescence quantum yield: $f_{\text {lum }} \approx$ $Q_{\mathrm{Ln}}^{\text {ligand }} \times \varepsilon_{\lambda}$ for which $Q_{\mathrm{Ln}}^{\text {ligand }}$ is the overall quantum yield, $\varepsilon_{\lambda}$ is the molar absorption coefficient, and $f_{\text {lum }}$ is the luminescence efficiency. ${ }^{[49]}$ In view of the insolubility of the coordination polymers in common solvents, their molar absorption coefficients could not be determined, which prevented us to estimate their luminescence efficiency. However, the molar absorption coefficient of the deprotonated ligand was calculated from a dilute aqueous solution of its sodium salt: $\varepsilon_{\text {max }}=4500 \mathrm{~L} \mathrm{~mol}^{-1} \mathrm{~cm}^{-1}$ (see Figure S2, Supporting Information), which is sizeable and which explains the large luminance of the lanthanide coordination polymers containing three such ligands per luminescent ion. However, the efficiency of the overall ligand-to-metal energy transfer $\left(\eta_{\text {sens }}\right)$ is also an important parameter. For lanthanide-containing compounds, it is defined as the efficacy with which energy is transferred from the feeding levels of the ligand onto the lanthanide ion excited states:

$Q_{\mathrm{Ln}}^{\text {ligand }}=\eta_{\text {sens }} \times Q_{\mathrm{Ln}}^{\mathrm{Ln}}$

for which $Q_{\mathrm{Ln}}^{\text {ligand }}$ and $Q_{\mathrm{Ln}}^{\mathrm{Ln}}$ are the overall quantum yield upon ligand excitation and the intrinsic quantum yield upon direct excitation of the rare earth ion, respectively.

For Eu-containing compounds a simplified equation leads to the radiative lifetime: ${ }^{[50]}$

$\frac{1}{\tau_{\text {rad }}}=A_{\mathrm{MD}, 0} \times n \times\left(\frac{I_{\text {tot }}}{I_{\mathrm{MD}}}\right)$

for which $A_{\mathrm{MD}, 0}$, a constant equal to $14.65 \mathrm{~s}^{-1}$, is the spontaneous emission probability of the magnetic dipole ${ }^{5} \mathrm{D}_{0 \rightarrow}{ }^{7} \mathrm{~F}_{1}, n$ is the refractive index, $I_{\text {tot }}$ is the integrated emission of the ${ }^{5} \mathrm{D}_{0} \rightarrow{ }^{7} \mathrm{~F}_{J}(J=0-6)$ transitions, and $I_{\mathrm{MD}}$ is the integrated emission of the ${ }^{5} \mathrm{D}_{0} \rightarrow{ }^{7} \mathrm{~F}_{1}$ transition. Relevant data are listed in Table 2.
Table 2. Observed $\left(\tau_{\mathrm{obs}}\right)$ and radiative luminescence lifetimes $\left(\tau_{\mathrm{rad}}\right)$, intrinsic $\left(Q_{\mathrm{Ln}}^{\mathrm{Ln}}\right)$ and absolute quantum yields $\left(Q_{\mathrm{Ln}}^{\mathrm{Ln}}\right)$, and sensitization efficiency $\left(\eta_{\text {sens }}\right)$ of the Eu-containing compound. ${ }^{[a]}$

\begin{tabular}{llllll}
\hline Compound & $\begin{array}{l}\tau_{\mathrm{rad}} \\
(\mathrm{ms})\end{array}$ & $\begin{array}{l}\tau_{\mathrm{obs}} \\
(\mathrm{ms})\end{array}$ & $\begin{array}{l}Q_{\mathrm{Ln}}^{\mathrm{Ln}} \\
(\%)\end{array}$ & $\begin{array}{l}Q_{\mathrm{Ln}}^{\mathrm{Ln}} \\
(\%)\end{array}$ & $\begin{array}{l}\eta_{\text {sens }} \\
(\%)\end{array}$ \\
\hline$\left[\mathrm{Eu}_{2}(\mathrm{bdc})_{3}\left(\mathrm{H}_{2} \mathrm{O}\right)_{4}\right]_{\infty}$ & 2.5 & $0.40(4)$ & $13.9(1.4)$ & 16.7 & 83 \\
\hline
\end{tabular}

[a] $\tau_{\text {rad }}, Q_{\mathrm{Ln}}^{\mathrm{Ln}}$, and $\eta_{\text {sens }}$ were calculated by assuming a refractive index of 1.50 .

These results indicate that the bdc ${ }^{2-}$ ligand is a good sensitizer for $\mathrm{Eu}^{3+}$ ions $\left(\eta_{\text {sens }}=83 \%\right)$. However, $Q_{\mathrm{Ln}}^{\mathrm{Ln}}$ is low. This indicates that nonradiative deactivation of the $\mathrm{Eu}^{3+}$ ions is important. This can be related to the presence of four coordination water molecules in the coordination sphere of the lanthanide ion. Indeed, the $\mathrm{Eu}^{3+}$ ion is known for being more sensitive to deactivation by $\mathrm{O}-\mathrm{H}$ oscillators than the $\mathrm{Tb}^{3+}$ ion. ${ }^{[51]}$

\section{Brightness Enhancement: Study of Heteronuclear $\left[\operatorname{Ln}_{2 x} \operatorname{Ln}_{2-2 x}(b d c)_{3}\left(\mathrm{H}_{2} \mathrm{O}\right)_{4}\right]_{\infty}$ Compounds with $0 \leq x \leq 1$; $\mathbf{L n}=\mathbf{T b}$ or $\mathbf{E u}$; and $\mathbf{L n}^{\prime}=\mathbf{Y}, \mathbf{L a}$, or $\mathbf{G d}$}

According to the crystal structure, lanthanide ions are close enough to give rise to intermetallic quenching. To evaluate this phenomenon, we synthesized heterometallic coordination polymers that involve one luminescent lanthanide ion $\left(\mathrm{Tb}^{3+}\right.$ or $\left.\mathrm{Eu}^{3+}\right)$ and one optically nonactive rare earth ion $\left(\mathrm{Y}^{3+}, \mathrm{La}^{3+}\right.$, or $\left.\mathrm{Gd}^{3+}\right)$ as optical dilutors. First, it can be noticed that the luminescence properties do not depend on the optically inactive rare earth metal that is involved. Given that the rare earth ions are randomly distributed over the metallic sites of the crystal structure, the addition of an optically inactive rare earth metal provokes an increase in the mean distance between the luminescent ions without perturbing the structure too much. As a matter of example, the relative intensities of the ${ }^{5} \mathrm{D}_{0} \rightarrow{ }^{7} \mathrm{~F}_{J}(J=0-4)$ transitions of several $\left[\mathrm{Gd}_{2 x} \mathrm{Eu}_{2-2 x}(\mathrm{bdc})_{3}\left(\mathrm{H}_{2} \mathrm{O}\right)_{4}\right]_{\infty}$ compounds are listed in Table 3 . From this table it clearly appears that the $\mathrm{Eu}^{3+}$ surroundings are essentially similar in all heterometallic compounds, because the relative intensities of all the transitions are almost identical in all of the compounds and because the radiative lifetime stays in a narrow 2.0-2.3 ms range, which is within experimental errors.

However, despite similar deactivation processes, these compounds exhibit different luminescence intensities (see Figure 7) and luminance: a dilution up to $x=0.25$ was beneficial, whereas further dilution resulted in a decrease in the luminescence intensity to a value comparable to that of the homometallic compound for $x=0.8$; finally, for $x \geq$ 0.9 , the effect was detrimental. This behavior can be interpreted as the result of a competition between two antagonist phenomena: (1) The more the $\mathrm{Eu}^{3+}$ ions are diluted, the weaker the intermetallic deactivation process is. (2) The more the $\mathrm{Eu}^{3+}$ ions are diluted, the less numerous per volumetric unit they are. A somewhat similar behavior was observed for heterometallic compounds that involve $\mathrm{Tb}^{3+}$ 
Table 3. Relative intensities of the ${ }^{5} \mathrm{D}_{0} \rightarrow{ }^{7} \mathrm{~F}_{\mathrm{J}}(J=0-4)$ transitions of the emission spectra, quantum yields, and lifetimes for $\left[\mathrm{Gd}_{2 x} \mathrm{Eu}_{2-2 x}(\mathrm{bdc})_{3}\left(\mathrm{H}_{2} \mathrm{O}\right)_{4}\right]_{\infty}$ with $2 x=1.90,1.75,1.50,0.5,0.25$, and 0.00

\begin{tabular}{|c|c|c|c|c|c|c|c|c|c|c|c|}
\hline \multirow[t]{2}{*}{ Compound } & \multicolumn{6}{|c|}{ Integrated intensity ${ }^{[\mathrm{a}]}$} & \multicolumn{2}{|c|}{ Lifetime (ms) } & \multicolumn{2}{|c|}{ Quantum yield (\%) } & \multirow{2}{*}{$\begin{array}{l}\text { Sensitization }(\%) \\
\eta_{\text {sens }}[\mathrm{b}, \mathrm{c}]\end{array}$} \\
\hline & $I_{J=0}$ & $I_{J=1}$ & $I_{J=2}$ & $I_{J=3}$ & $I_{J=4}$ & $I_{\text {tot }}$ & $\tau_{\mathrm{rad}^{[\mathrm{c}]}}$ & $\tau_{\mathrm{obs}}^{[b]}$ & $Q_{\mathrm{Eu}}^{\mathrm{Eu}[\mathrm{c}]}$ & $Q_{\mathrm{L}}^{\mathrm{Eu}[\mathrm{b}]}$ & \\
\hline$\left[\mathrm{Gd}_{1.90} \mathrm{Eu}_{0.10}(\mathrm{bdc})_{3}\left(\mathrm{H}_{2} \mathrm{O}\right)_{4}\right]_{\infty}$ & 0.01 & 1.00 & 5.70 & 0.12 & 2.02 & 4.93 & 2.3 & $0.46(5)$ & 20.3 & $16.9(1.7)$ & 83 \\
\hline$\left[\mathrm{Gd}_{1.75} \mathrm{Eu}_{0.25}(\mathrm{bdc})_{3}\left(\mathrm{H}_{2} \mathrm{O}\right)_{4}\right]_{\infty}$ & 0.01 & 1.00 & 5.71 & 0.11 & 1.98 & 4.89 & 2.3 & $0.47(5)$ & 20.3 & $15.7(1.6)$ & 77 \\
\hline$\left[\mathrm{Gd}_{1.50} \mathrm{Eu}_{0.50}(\mathrm{bdc})_{3}\left(\mathrm{H}_{2} \mathrm{O}\right)_{4}\right]_{\infty}$ & 0.01 & 1.00 & 5.77 & 0.14 & 2.24 & 4.87 & 2.2 & $0.48(5)$ & 21.8 & $14.5(1.4)$ & 67 \\
\hline$\left[\mathrm{Gd}_{1.00} \mathrm{Eu}_{1.00}(\mathrm{bdc})_{3}\left(\mathrm{H}_{2} \mathrm{O}\right)_{4}\right]_{\infty}$ & 0.02 & 1.00 & 6.08 & 0.22 & 2.63 & 5.03 & 2.0 & $0.47(5)$ & 22.9 & $16.2(1.6)$ & 71 \\
\hline$\left[\mathrm{Gd}_{0.50} \mathrm{Eu}_{1.50}(\mathrm{bdc})_{3}\left(\mathrm{H}_{2} \mathrm{O}\right)_{4}\right]_{\infty}$ & 0.02 & 1.00 & 5.80 & 0.16 & 2.32 & 4.97 & 2.2 & $0.45(4)$ & 20.5 & $15.1(1.5)$ & 74 \\
\hline$\left[\mathrm{Gd}_{0.25} \mathrm{Eu}_{1.75}(\mathrm{bdc})_{3}\left(\mathrm{H}_{2} \mathrm{O}\right)_{4}\right]_{\infty}$ & 0.01 & 1.00 & 5.80 & 0.16 & 2.28 & 5.09 & 2.2 & $0.45(4)$ & 20.6 & $14.2(1.4)$ & 69 \\
\hline$\left[\mathrm{Eu}_{2.00}(\mathrm{bdc})_{3}\left(\mathrm{H}_{2} \mathrm{O}\right)_{4}\right]_{\infty}$ & 0.02 & 1.00 & 5.10 & 0.15 & 1.78 & 4.00 & 2.5 & $0.40(4)$ & 16.7 & $13.9(1.4)$ & 83 \\
\hline
\end{tabular}

[a] Normalized versus the ${ }^{5} \mathrm{D}_{0} \rightarrow{ }^{7} \mathrm{~F}_{1}$ transition $( \pm 5 \%)$. [b] The measured values of $Q_{\mathrm{L}}^{\mathrm{Eu}}, \tau_{\mathrm{obs}}$, and $\eta_{\text {sens }}$ are calculated values considering $n$ $=1.5$. [c] Errors on the values of $\tau_{\text {rad }}, Q \mathrm{Eu}$ Eu and $\eta_{\text {sens }}$ can be estimated to 10,15 , and $20 \%$ respectively.
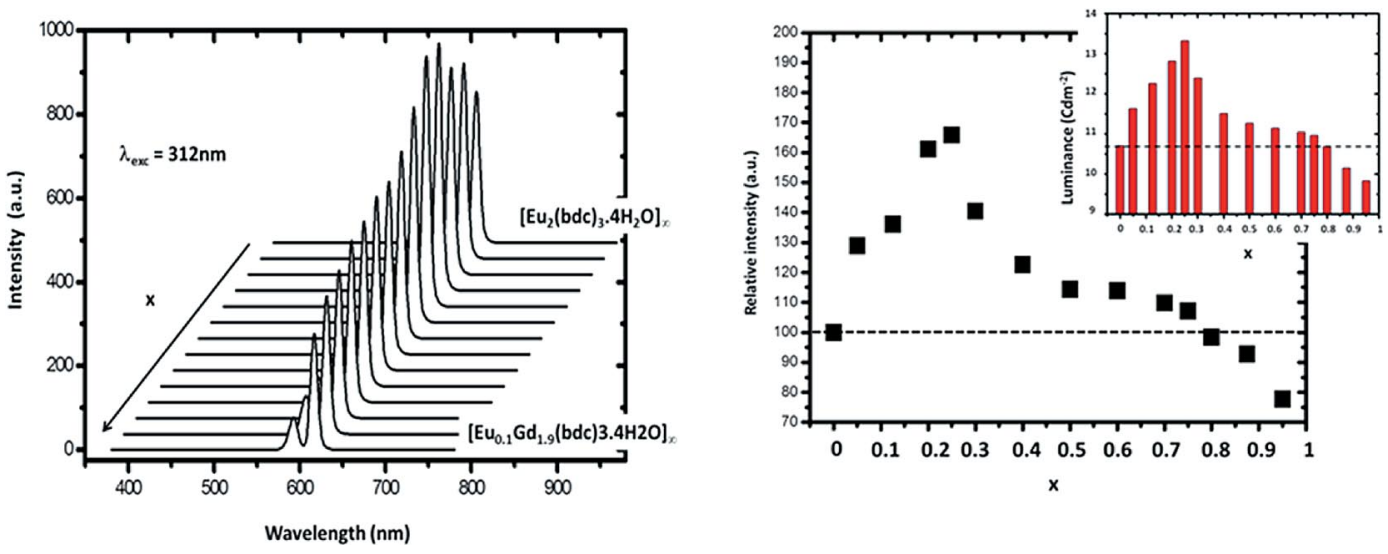

Figure 7. Left: Emission spectra of $\left[\mathrm{Gd}_{2 x} \mathrm{Eu}_{2-2 x}(\mathrm{bdc})_{3}\left(\mathrm{H}_{2} \mathrm{O}\right)_{4}\right]_{\infty}$ versus $x$ under UV irradiation $\left(\lambda_{\text {exc }}=312 \mathrm{~nm}\right)$. Right: Integrated intensity of the emission transitions versus $x$. Dotted line indicates the relative intensity of the Eu-based homonuclear compound. Inset: Related luminance measurements.
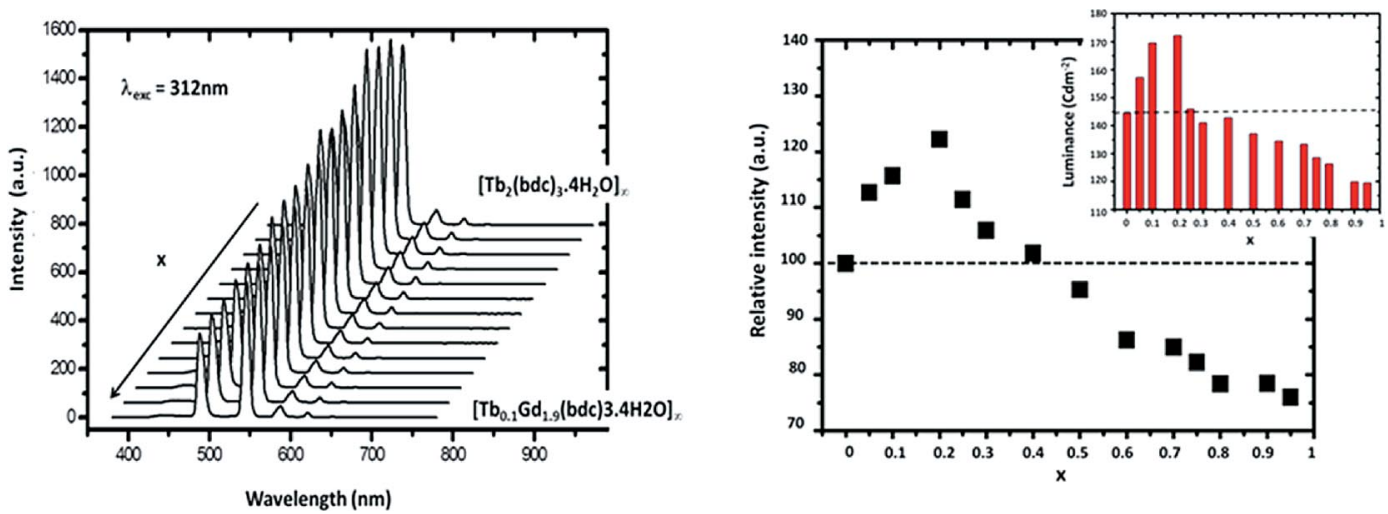

Figure 8. Left: Emission spectra of $\left[\mathrm{Gd}_{2 x} \mathrm{~Tb}_{2-2 x}(\mathrm{bdc})_{3}\left(\mathrm{H}_{2} \mathrm{O}\right)_{4}\right]_{\infty}$ versus $x$ under UV irradiation $\left(\lambda_{\text {exc }}=312 \mathrm{~nm}\right)$. Right: Integrated intensity of the emission transitions versus $x$. Dotted line indicates the relative intensity of the Tb-based homonuclear compound. Inset: Related luminance measurements.

ions, but the beneficial range was limited to $x<0.4$, and all other values led to less luminescent compounds compared to the homometallic one (see Figure 8).

These results confirm that some intermetallic quenching exists between optically active lanthanide ions. The variations in luminescence intensity observed can be related to the crystal structure. Indeed, it is commonly admitted that dipole-dipole intermetallic energy transfer is less efficient if the metallic ions are more than $10 \AA$ apart from each other. ${ }^{[52,53]}$ In the present case, a specific lanthanide ion is surrounded by eight other metal ions in a sphere with approximately $10 \AA$ radius (Scheme 2). Therefore, a given optically active lanthanide ion is statistically surrounded by eight optically inactive lanthanide ion if $x$ is greater than 
$8 / 9(x \approx 0.9)$ and by eight optically active lanthanide ions if $x$ is smaller than $1 / 9(x \approx 0.1)$.

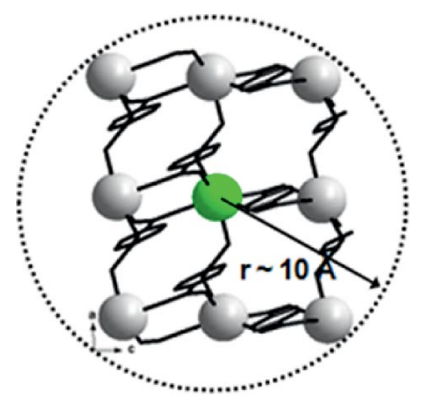

Scheme 2. Surrounding of a lanthanide ion in a $10 \AA$ radius sphere.

This suggests that, as far as $\mathrm{Eu}^{3+}$ or $\mathrm{Tb}^{3+}$ are concerned, the most relevant parameter for intermetallic deactivation is not the mean distance between optically active lanthanide ions but the absence or presence of another optically active lanthanide ion in the neighborhood. This is in agreement with what has already been suggested previously. ${ }^{[36]}$

These results are also interesting as far as technological applications are concerned. Indeed, they suggest that it is possible to synthesize heteronuclear compounds containing only a few percent of $\mathrm{Eu}^{3+}$ or $\mathrm{Tb}^{3+}$ ions and exhibiting luminescence almost as bright as that exhibited by the corresponding homonuclear compound (see Table 4). They also suggest that it is possible to enhance the brightness without modifying the color of a luminescent compound by adding a few percent of inactive lanthanide ions (Figure S3, Supporting Information). This is interesting because optically active rare earth metals are much more expensive than lanthanum.

Table 4. Colorimetric and luminance data for $\left[\mathrm{La}_{2 x} \mathrm{~Tb}_{2-2 x}(\mathrm{bdc})_{3^{-}}\right.$ $\left.\left(\mathrm{H}_{2} \mathrm{O}\right)_{4}\right]_{\infty}$ with $2 x=1.95,1.8,1.60,1.0,0.4$, and 0.00 .

\begin{tabular}{llll}
\hline Compound & $x$ & $y$ & $\begin{array}{l}\left.\text { Luminance }^{[\mathrm{aa}}\right] \\
\left(\mathrm{Cd} \mathrm{m}^{-2}\right)\end{array}$ \\
\hline$\left[\mathrm{La}_{1.95} \mathrm{~Tb}_{0.05}(\mathrm{bdc})_{3}\left(\mathrm{H}_{2} \mathrm{O}\right)_{4}\right]_{\infty}$ & $0.33(1)$ & $0.59(1)$ & $85(2)$ \\
{$\left[\mathrm{La}_{1.80} \mathrm{~Tb}_{0.20}(\mathrm{bdc})_{3}\left(\mathrm{H}_{2} \mathrm{O}\right)_{4}\right]_{\infty}$} & $0.33(1)$ & $0.59(1)$ & $112(2)$ \\
{$\left[\mathrm{La}_{1.60} \mathrm{~Tb}_{0.40}(\mathrm{bdc})_{3}\left(\mathrm{H}_{2} \mathrm{O}\right)_{4}\right]_{\infty}$} & $0.33(1)$ & $0.59(1)$ & $122(2)$ \\
{$\left[\mathrm{La}_{1.00} \mathrm{~Tb}_{1.00}(\mathrm{bdc})_{3}\left(\mathrm{H}_{2} \mathrm{O}\right)_{4}\right]_{\infty}$} & $0.32(1)$ & $0.60(1)$ & $127(2)$ \\
{$\left[\mathrm{La}_{0.40} \mathrm{~Tb}_{1.60}(\mathrm{bdc})_{3}\left(\mathrm{H}_{2} \mathrm{O}\right)_{4}\right]_{\infty}$} & $0.34(1)$ & $0.58(1)$ & $142(2)$ \\
{$\left[\mathrm{Tb}_{2.00}(\mathrm{bdc})_{3}\left(\mathrm{H}_{2} \mathrm{O}\right)_{4}\right]_{\infty}$} & $0.34(1)$ & $0.57(1)$ & $143(2)$ \\
\hline
\end{tabular}

[a] The values represent the luminous flux weighted by the spectral response of the human eye.

This optical dilution strategy was also used for the less luminescent $\mathrm{Sm}$ and Dy derivatives to enhance their brightness. For both series, the observed behaviors were different from those observed for the Eu- and Tb-containing compounds (see Figure 9).

Figure 9 suggests that for these two series of compounds, the dilution of the optically active ion induces a monotonous increase in the overall quantum yields. Actually, for $\left[\mathrm{Gd}_{1.5} \mathrm{Sm}_{0.5}(\mathrm{bdc})_{3}\left(\mathrm{H}_{2} \mathrm{O}\right)_{4}\right]_{\infty}$, the overall quantum yield is $0.26(3) \%\left[\tau_{\mathrm{obs}}=7.7(8) \mu \mathrm{s}\right]$, which is three times greater than that measured for homonuclear $\left[\mathrm{Sm}_{2}(\mathrm{bdc})_{3}\left(\mathrm{H}_{2} \mathrm{O}\right)_{4}\right]_{\infty}$. For $\left[\mathrm{Gd}_{1.5} \mathrm{Dy}_{0.5}(\mathrm{bdc})_{3}\left(\mathrm{H}_{2} \mathrm{O}\right)_{4}\right]_{\infty}$, the overall quantum yield is $1.10(10) \%\left[\tau_{\mathrm{obs}}=5.7(3) \mu \mathrm{s}\right]$, which is more than four times

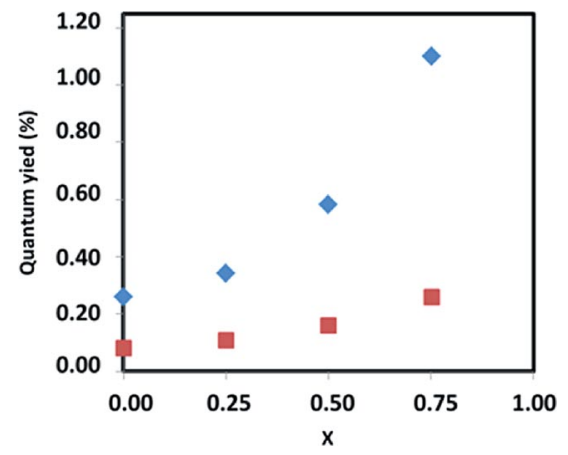

Figure 9. Overall quantum yields $Q_{\mathrm{S}}^{\text {ligand }}$ (blue) and $Q_{\mathrm{Dy}}^{\text {ligand }}$ (red) for $\left[\mathrm{Gd}_{2 x} \mathrm{Sm}_{2-2 x}(\mathrm{bdc})_{3}\left(\mathrm{H}_{2} \mathrm{O}\right)_{4}\right]_{\infty}$ and $\left[\mathrm{Gd}_{2 x} \mathrm{Dy}_{2-2 x}(\mathrm{bdc})_{3}\left(\mathrm{H}_{2} \mathrm{O}\right)_{4}\right]_{\infty}$ with $x$ $=0.00,0.25,0.50$, and 1.00. Quantum yields were calculated on the basis of the ${ }^{4} \mathrm{G}_{5 / 2} \rightarrow{ }^{6} \mathrm{H}_{5 / 2}$ and ${ }^{4} \mathrm{~F}_{9 / 2} \rightarrow{ }^{6} \mathrm{H}_{13 / 2}$ transitions for the two compounds, respectively.

greater than that measured for homonuclear $\left[\mathrm{Dy}_{2}(\mathrm{bdc})_{3^{-}}\right.$ $\left.\left(\mathrm{H}_{2} \mathrm{O}\right)_{4}\right]_{\infty}$. This could suggest that in $\left[\mathrm{Sm}_{2}(\mathrm{bdc})_{3}\left(\mathrm{H}_{2} \mathrm{O}\right)_{4}\right]_{\infty}$ and $\left[\mathrm{Dy}_{2}(\mathrm{bdc})_{3}\left(\mathrm{H}_{2} \mathrm{O}\right)_{4}\right]_{\infty}$, the intermetallic $\mathrm{Ln}^{\mathrm{III}}$-to- $\mathrm{Ln}^{\mathrm{III}} \mathrm{de}-$ activation process is more efficient than the $\mathrm{Eu}^{\mathrm{III}}-$ to- $\mathrm{Eu}^{\mathrm{III}}$ and $\mathrm{Tb}^{\mathrm{III}}$-to- $\mathrm{Tb}^{\mathrm{III}}$ processes in $\left[\mathrm{Eu}_{2}(\mathrm{bdc})_{3}\left(\mathrm{H}_{2} \mathrm{O}\right)_{4}\right]_{\infty}$ and $\left[\mathrm{Tb}_{2}(\mathrm{bdc})_{3}\left(\mathrm{H}_{2} \mathrm{O}\right)_{4}\right]_{\infty}$, respectively, as the dilution effect is more pronounced.

\section{Modulation of the Luminescence Color: Study of Heteronuclear $\left[\mathrm{Tb}_{2 x} \mathrm{Eu}_{2-2 x}(\mathrm{bdc})_{3}\left(\mathrm{H}_{2} \mathrm{O}\right)_{4}\right]_{\infty}$ Compounds with $0 \leq x \leq 1$}

The emission spectra of the family of heteronuclear compounds containing both $\mathrm{Eu}^{3+}$ and $\mathrm{Tb}^{3+}$ ions are displayed in Figure 10. First, this study reveals that there is a nonlinear evolution of the colorimetric and spectroscopic properties of these compounds versus the $\mathrm{Tb} / \mathrm{Eu}$ ratio.

The luminescence contributions to the total emission spectra of the $\mathrm{Eu}^{\mathrm{III}}$ and $\mathrm{Tb}^{\mathrm{III}}$ ions were estimated on the basis of the ${ }^{5} \mathrm{D}_{0} \rightarrow{ }^{7} \mathrm{~F}_{0}$ and ${ }^{5} \mathrm{D}_{4} \rightarrow{ }^{7} \mathrm{~F}_{5}$ transitions, respectively, because they do not overlap with other transitions. Given that all of the compounds are isostructural and that the metallic ions are perfectly randomly distributed, we assumed that the relative intensities of the different peaks are similar to those observed in the corresponding homonuclear compounds (Figure 11).

As can be seen from Figure 11, the $\mathrm{Tb}^{3+}$ quantum yield is very low until $x$ becomes greater than 0.9 . This suggests that the Tb-to-Eu energy transfer is quite efficient (see Table 5) as soon as only one $\mathrm{Eu}^{3+}$ ion enters into the neighborhood of the $\mathrm{Tb}^{3+}$ ions.

The yield of this Tb-to-Eu energy transfer $\left(\eta_{\mathrm{ET}}\right)$ can be estimated by using the relationship

$\eta_{\mathrm{ET}}=1-\frac{\tau_{\mathrm{obs}}}{\tau_{0}}$

in which $\tau_{\mathrm{obs}}$ and $\tau_{0}$ are the lifetimes in the presence and

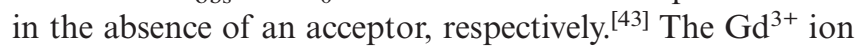
with its first excited levels above the luminescent levels of the $\mathrm{Tb}^{3+}$ ion and above the ligand triplet state cannot act as an acceptor. Therefore, by replacing $\mathrm{Eu}^{3+}$ ions by $\mathrm{Gd}^{3+}$ 


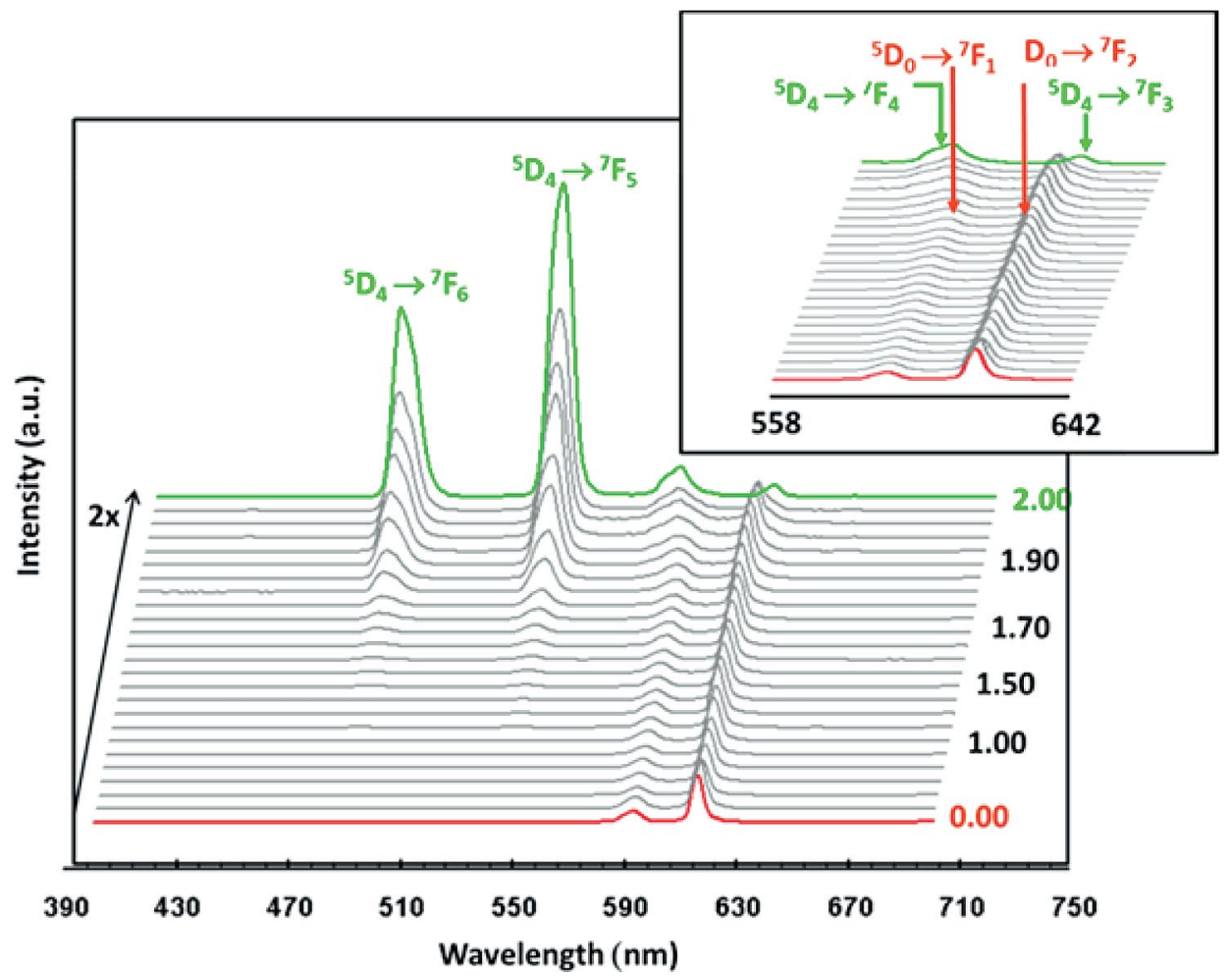

Figure 10. Luminescence spectra of $\left[\mathrm{Tb}_{2 x} \mathrm{Eu}_{2-2 x}(\mathrm{bdc})_{3}\left(\mathrm{H}_{2} \mathrm{O}\right)_{4}\right]_{\infty}$ with $0 \leq x \leq 1$ under UV irradiation $\left(\lambda_{\operatorname{exc}}=312 \mathrm{~nm}\right)$.

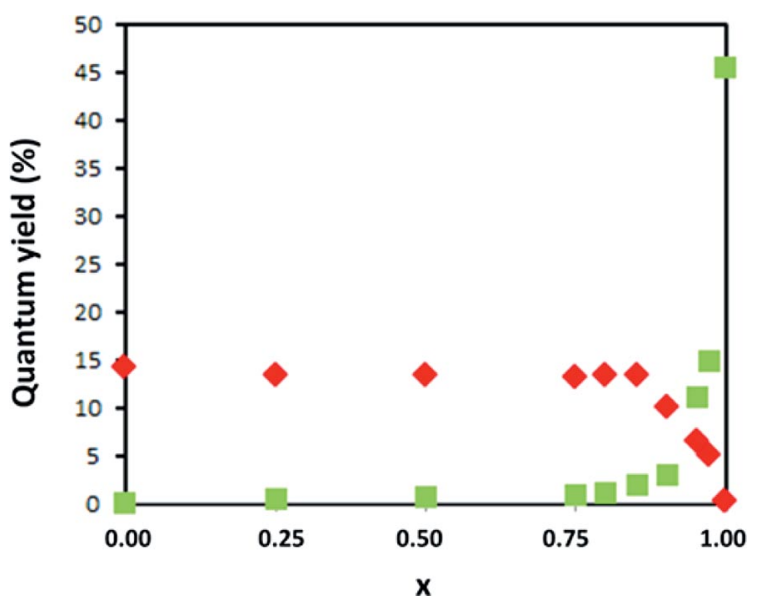

Figure 11. $Q_{\mathrm{Eu}}^{\text {ligand }}\left(\right.$ red) and $Q_{\mathrm{Tb}}^{\text {ligand }}\left(\right.$ green) versus $x$ for $\left[\mathrm{Tb}_{2 x} \mathrm{Eu}_{2-2 x^{-}}\right.$ $\left.(\mathrm{bdc})_{3}\left(\mathrm{H}_{2} \mathrm{O}\right)_{4}\right]_{\infty}$.

Table 5. Quantum yields and lifetimes for $\left[\mathrm{Tb}_{2 x} \mathrm{Eu}_{2-2 x}(\mathrm{bdc})_{3^{-}}\right.$ $\left.\left(\mathrm{H}_{2} \mathrm{O}\right)_{4}\right]_{\infty}$ with $x=1,0.75,0.5,0.25$, and 0 .

\begin{tabular}{lllll}
\hline Compound & $\begin{array}{l}\mathrm{Eu}^{3+} \\
\tau_{\text {obs }} \\
(\mathrm{ms})\end{array}$ & $\begin{array}{l}Q_{\mathrm{Eu}}^{\text {ligand }} \\
(\%)\end{array}$ & $\begin{array}{l}\mathrm{Tb}^{3+} \\
\tau_{\text {obs }} \\
(\mathrm{ms})\end{array}$ & $\begin{array}{l}Q_{\mathrm{Tb}}^{\text {ligand }} \\
(\%)\end{array}$ \\
\hline$\left[\mathrm{Tb}_{2}(\mathrm{bdc})_{3}\left(\mathrm{H}_{2} \mathrm{O}\right)_{4}\right]_{\infty}$ & - & - & $1.10(1)$ & $45.5(4.5)$ \\
{$\left[\mathrm{Tb}_{1.50} \mathrm{Eu}_{0.5}(\mathrm{bdc})_{3}\left(\mathrm{H}_{2} \mathrm{O}\right)_{4}\right]_{\infty}$} & $0.48(1)$ & $13.1(1.2)$ & $0.088(1)$ & $0.97(1.0)$ \\
{$\left[\mathrm{Tb}_{1.0} \mathrm{Eu}_{1.0}(\mathrm{bdc})_{3}\left(\mathrm{H}_{2} \mathrm{O}\right)_{4}\right]_{\infty}$} & $0.47(1)$ & $12.3(1.2)$ & $0.043(1)$ & $0.56(1.0)$ \\
{$\left[\mathrm{Tb}_{0.5} \mathrm{Eu}_{1.5}(\mathrm{bdc})_{3}\left(\mathrm{H}_{2} \mathrm{O}\right)_{4}\right]_{\infty}$} & $0.45(1)$ & $11.9(1.1)$ & $0.025(1)$ & $0.19(1.0)$ \\
{$\left[\mathrm{Eu}_{2}(\mathrm{bdc})_{3}\left(\mathrm{H}_{2} \mathrm{O}\right)_{4}\right]_{\infty}$} & $0.42(1)$ & $13.9(1.4)$ & - & - \\
\hline
\end{tabular}

ions it is possible to measure $\tau_{0}$ and therefore to calculate $\eta_{\text {ET. }}$ These calculations demonstrate (see Table 6) that the Tb-to-Eu energy transfer is very efficient.

Table 6. Tb-to-Eu energy-transfer efficiency for $\left[\mathrm{Tb}_{2 x} \mathrm{Eu}_{2-2 x}(\mathrm{bdc})_{3^{-}}\right.$ $\left.\left(\mathrm{H}_{2} \mathrm{O}\right)_{4}\right]_{\infty}$ with $x=0.75,0.5$, and 0.25 .

\begin{tabular}{llll}
\hline Compound & $\tau_{\text {obs }}(\mathrm{ms})$ & $\tau_{0}(\mathrm{~ms})$ & $\eta_{\text {ET }}(\%)$ \\
\hline$\left[\mathrm{Tb}_{1.50} \mathrm{Eu}_{0.5}(\mathrm{bdc})_{3}\left(\mathrm{H}_{2} \mathrm{O}\right)_{4}\right]_{\infty}$ & $0.088(1)$ & $1.15(1)$ & 90 \\
{$\left[\mathrm{~Tb}_{1.0} \mathrm{Eu}_{1.0}(\mathrm{bdc})_{3}\left(\mathrm{H}_{2} \mathrm{O}\right)_{4}\right]_{\infty}$} & $0.043(1)$ & $1.15(1)$ & 95 \\
{$\left[\mathrm{~Tb}_{0.5} \mathrm{Eu}_{1.5}(\mathrm{bdc})_{3}\left(\mathrm{H}_{2} \mathrm{O}\right)_{4}\right]_{\infty}$} & $0.025(1)$ & $1.16(1)$ & 97 \\
\hline
\end{tabular}

Some of the compounds of the series were studied in more detail (see Table 7). These heteronuclear compounds present radiative and nonradiative lifetimes and quantum yields that are very similar to one another and very near to those observed for the Eu-containing homonuclear compound. As expected, the sensitization efficiency is smaller (about $-20 \%$ ) as a result of the double energy-transfer process (bdc ${ }^{2-}$-to-Tb-to-Eu).

The quantitative results of the study of the $1: 1 \mathrm{Eu} / \mathrm{Tb}$ compound are reported in Scheme 3, which summarizes the different energy migration processes in this compound.

Colorimetric data were also recorded. Numerical results are listed in Table S1 (Supporting Information), whereas color coordinates are reported in Figure 12. They are localized on a straight line extending from the coordinates of the Eu-containing homonuclear compound to the coordinates of the Tb-containing one. The evolution of the colori- 
Table 7. Relative intensities of the ${ }^{5} \mathrm{D}_{0} \rightarrow{ }^{7} \mathrm{~F}_{\mathrm{J}}(J=0-4)$ transitions of the emission spectra, quantum yields, and lifetimes for [Eu ${ }_{2 x} \mathrm{~Tb}_{2-2 x^{-}}$ $\left.(\mathrm{bdc})_{3}\left(\mathrm{H}_{2} \mathrm{O}\right)_{4}\right]_{\infty}$ with $2 x=0.5,1.0$, and 1.50 .

\begin{tabular}{llllllllllll}
\hline Compound & \multicolumn{3}{c}{ Integrated intensity[a] } & \multicolumn{3}{c}{ Lifetime $(\mathrm{ms})$} & \multicolumn{2}{c}{ Quantum yield } & \multicolumn{2}{c}{ Sensitization } \\
& $I_{J=0}$ & $I_{\mathrm{J}=1}$ & $I_{\mathrm{J}=2}$ & $I_{\mathrm{J}=3}$ & $I_{\mathrm{J}=4}$ & $I_{\text {tot }}$ & $\tau_{\text {rad }}^{\text {[c] }}$ & $\tau_{\text {obs }}$ [b] & $Q_{\mathrm{Eu}}^{\mathrm{Eu}[\mathrm{c}]}$ & $Q_{\mathrm{L}}^{\mathrm{Eu}[\mathrm{b}]}$ & $\eta_{\mathrm{sens}}$ \\
\hline$\left[\mathrm{Eu}_{0.50} \mathrm{~Tb}_{1.50}(\mathrm{bdc})_{3}\left(\mathrm{H}_{2} \mathrm{O}\right)_{4}\right]_{\infty}$ & 0.01 & 1.00 & 5.26 & 0.14 & 1.92 & 4.12 & 2.42 & $0.47(1)$ & 19.8 & $13.1(1.3)$ & 66 \\
{$\left[\mathrm{Eu}_{1.00} \mathrm{~Tb}_{1.00}(\mathrm{bdc})_{3}\left(\mathrm{H}_{2} \mathrm{O}\right)_{4}\right]_{\infty}$} & 0.01 & 1.00 & 5.20 & 0.14 & 1.87 & 4.07 & 2.46 & $0.46(1)$ & 19.1 & $12.3(1.2)$ & 64 \\
{$\left[\mathrm{Eu}_{1.50} \mathrm{~Tb}_{0.50}(\mathrm{bdc})_{3}\left(\mathrm{H}_{2} \mathrm{O}\right)_{4}\right]_{\infty}$} & 0.01 & 1.00 & 5.20 & 0.14 & 1.87 & 4.07 & 2.46 & $0.46(1)$ & 19.1 & $12.3(1.2)$ & 64 \\
{$\left[\mathrm{Eu}_{2.00}(\mathrm{bdc})_{3}\left(\mathrm{H}_{2} \mathrm{O}\right)_{4}\right]_{\infty}$} & 0.02 & 1.00 & 5.10 & 0.15 & 1.78 & 4.00 & 2.51 & $0.40(1)$ & 16.7 & $13.9(1.4)$ & 83 \\
\hline
\end{tabular}

[a] Normalized versus the ${ }^{5} \mathrm{D}_{0} \rightarrow{ }^{7} \mathrm{~F}_{1}$ transition $( \pm 5 \%)$. [b] The measured values of $Q_{\mathrm{L}}^{\mathrm{Eu}}, \tau_{\text {obs }}$, and $\eta_{\text {sens }}$ are calculated values considering $n$ $=1.5$. [c] Errors on the values of $\tau_{\text {rad }}, Q \mathrm{Eu}$, and $\eta_{\text {sens }}$ can be estimated to 10,15 , and $20 \%$ respectively.

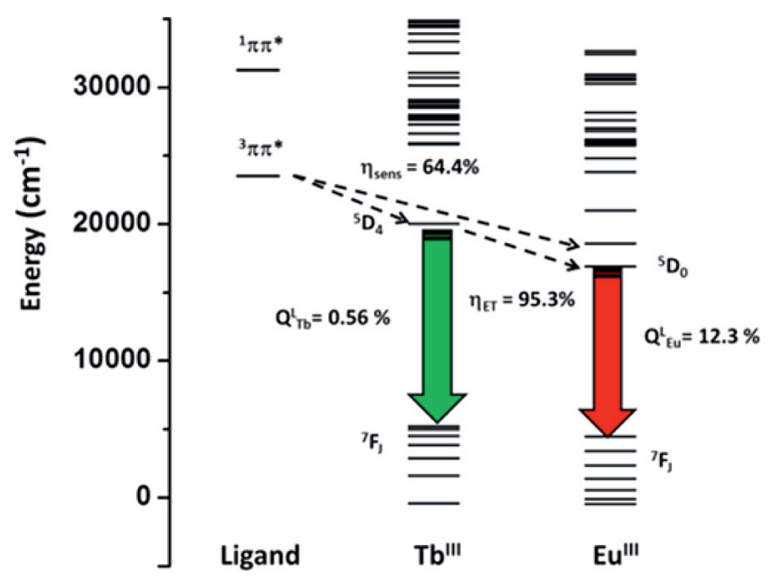

Scheme 3. Suggested mechanism of luminescence sensitization in $\left[\mathrm{Eu}_{1.00} \mathrm{~Tb}_{1.00}(\mathrm{bdc})_{3}\left(\mathrm{H}_{2} \mathrm{O}\right)_{4}\right]_{\infty}$.

metric coordinates versus $x$ and the luminance data (Figure 13) is very similar to the evolution of the overall quantum yields $Q_{\mathrm{Eu}}^{\text {ligand }}$ and $Q_{\mathrm{Tb}}^{\text {ligand }}$ (see Figure 11$)$. Actually, as expected, the spectroscopic and colorimetric data are closely related.

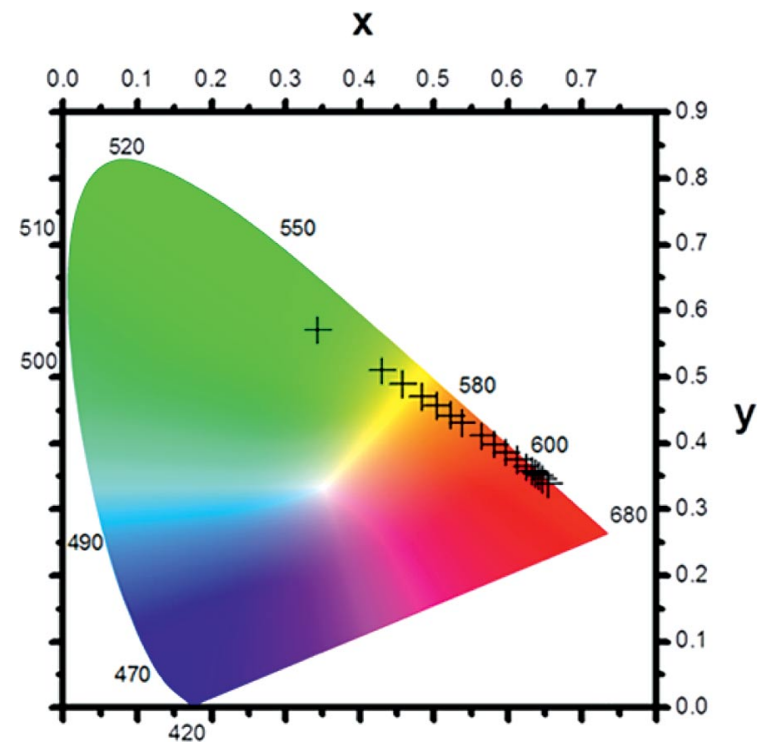

Figure 12. Color coordinates for heteronuclear $\left[\mathrm{Tb}_{2 x} \mathrm{Eu}_{2-2 x}(\mathrm{bdc})_{3^{-}}\right.$ $\left.\left(\mathrm{H}_{2} \mathrm{O}\right)_{4}\right]_{\infty}$ compounds with $0 \leq x \leq 1$.
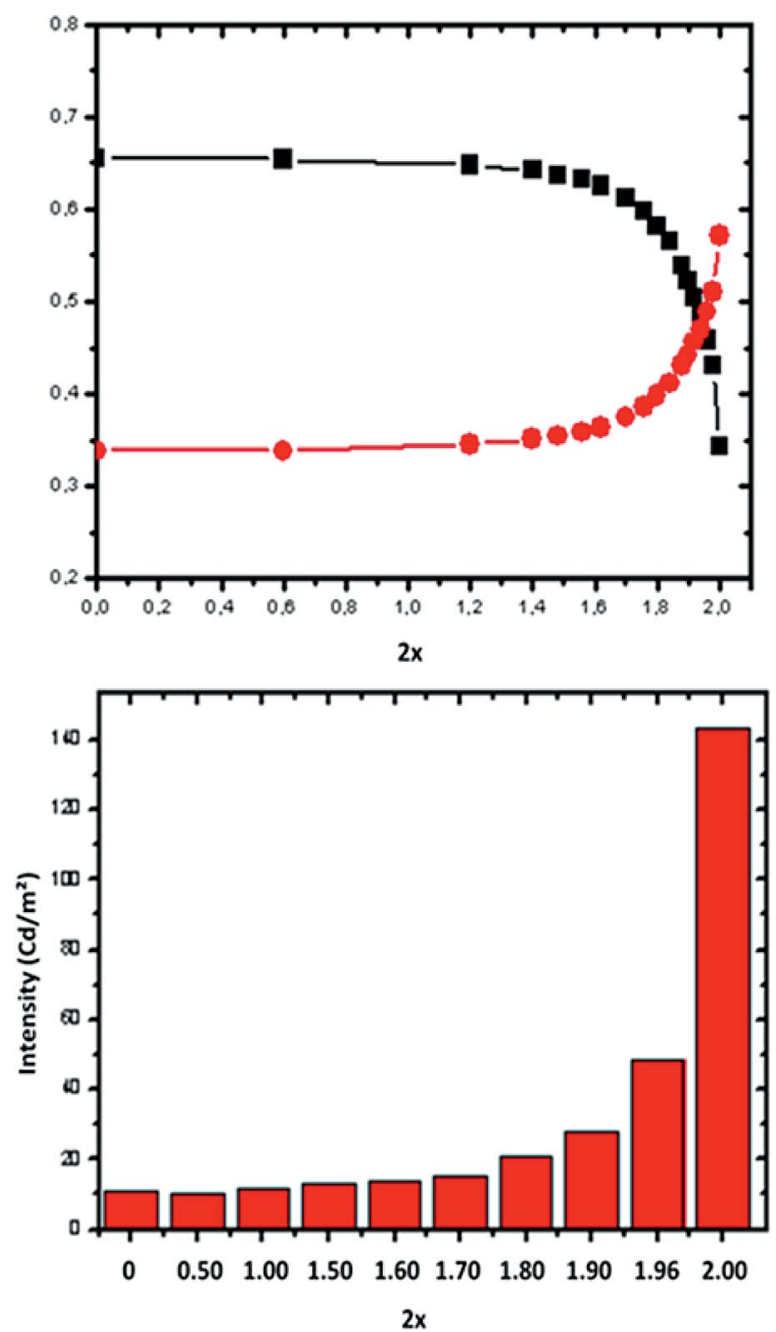

Figure 13. Colorimetric (top) and luminance (bottom) data for heteronuclear $\left[\mathrm{Tb}_{2 x} \mathrm{Eu}_{2-2 x}(\mathrm{bdc})_{3}\left(\mathrm{H}_{2} \mathrm{O}\right)_{4}\right]_{\infty}$ compounds with $0 \leq 2 x \leq$ 2. Left: Color coordinates $x$ and $y$ are drawn in black and red, respectively.

Combined Modulation of the Luminescence Color and Brightness: Study of Heterotrimetallic $\left[\mathbf{T b}_{2 x} \mathbf{E u}_{2 y} \mathbf{L a}_{2-2 x-2 y^{-}}\right.$ $\left.(\text { bdc })_{3}\left(\mathrm{H}_{2} \mathrm{O}\right)_{4}\right]_{\infty}$ Compounds with $0 \leq x, y \leq 1$

By playing with dilution by $\mathrm{La}^{3+}$ and $\mathrm{Tb}$-to-Eu energy transfer modulated by the $\mathrm{Tb} / \mathrm{Eu}$ ratio, it is possible to tune both the color coordinates and the brightness of this family 
of compounds. Pictures obtained under UV irradiation of heterotrimetallic $\left[\mathrm{Tb}_{2 x} \mathrm{Eu}_{2 y} \mathrm{La}_{2-2 x-2 y}(\mathrm{bdc})_{3}\left(\mathrm{H}_{2} \mathrm{O}\right)_{4}\right]_{\infty} \quad$ compounds with $2 x$ and $2 y$ between 0 and 2 are reported in Figure 14. It is noticeable that the trichromatic coordinates are located on the same straight line as the trichromatic coordinates of the heterobimetallic $\left[\mathrm{Tb}_{2 x} \mathrm{Eu}_{2-2 x}(\mathrm{bdc})_{3}\right.$ $\left.\left(\mathrm{H}_{2} \mathrm{O}\right)_{4}\right]_{\infty}$ compounds. Moreover, the emission color and brightness are correlated and strongly depend on dilution and relative chemical composition.
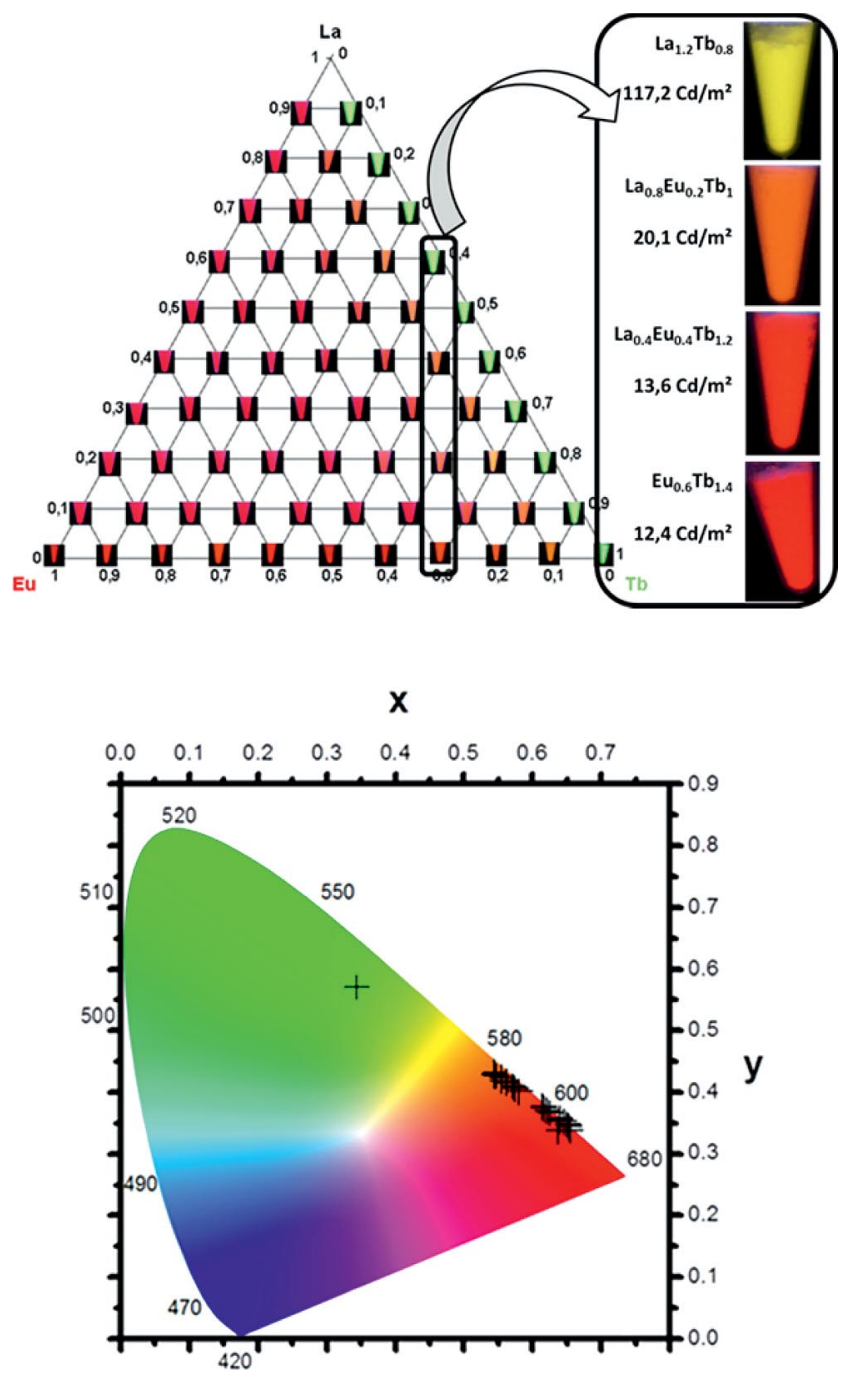

Figure 14. Top: Pictures obtained under UV irradiation of heterotrimetallic $\left[\mathrm{Tb}_{2 x} \mathrm{Eu}_{2 y} \mathrm{La}_{2-2 x-2 y}(\mathrm{bdc})_{3}\left(\mathrm{H}_{2} \mathrm{O}\right)_{4}\right]_{\infty}$ compounds with $2 x$ and $2 y$ between 0 and 2 . Bottom: Color coordinates.

Extension of the Accessible Colorimetric Area: Study of Heteronuclear $\left[\left.\operatorname{Ln}_{2 x} D y_{2-2 x}(b d c)_{3}\left(H_{2} O\right)_{4}\right|_{\infty}\right.$ Compounds with $0 \leq x \leq 1$ and $\mathrm{Ln}=\mathrm{Tb}$ or $\mathrm{Eu}$

Some heterometallic $\left[\mathrm{Dy}_{2 x} \mathrm{Eu}_{2-2 x}(\mathrm{bdc})_{3}\left(\mathrm{H}_{2} \mathrm{O}\right)_{4}\right]_{\infty}$ compounds were also briefly studied because of the yellow emission of $\mathrm{Dy}^{3+}$. Their emission spectra are reported in Figure 15 .

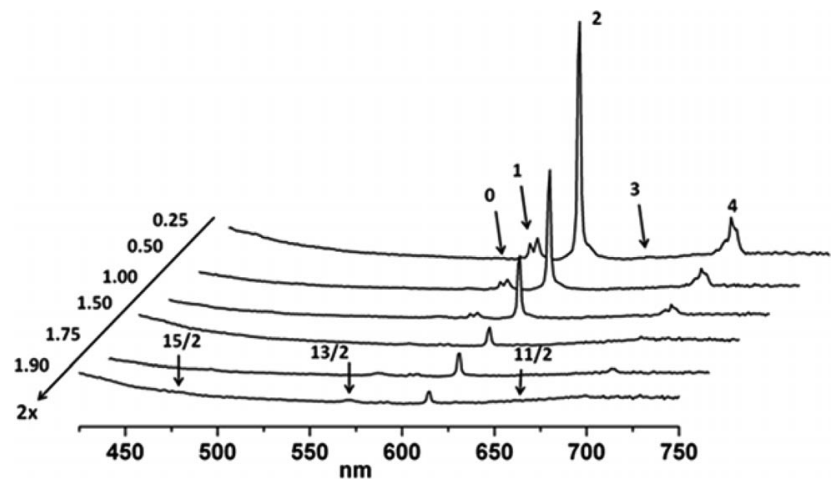

Figure 15. Emission spectra of $\left[\mathrm{Dy}_{2 x} \mathrm{Eu}_{2-2 x}(\mathrm{bdc})_{3}\left(\mathrm{H}_{2} \mathrm{O}\right)_{4}\right]_{\infty}$ with $2 x$ $=1.90,1.75,1.50,1.00,0.50$, and $0.25 ; \lambda_{\text {exc }}=312 \mathrm{~nm}$.

Overall quantum yields were measured for both the $\mathrm{Dy}^{3+}$ and $\mathrm{Eu}^{3+}$ ions. However, the lifetimes were only measured for the $\mathrm{Eu}^{3+}$ ions because the lifetimes of the $\mathrm{Dy}^{3+}$ ions were too short to measure. The data are listed in Table 8 .

Table 8. Quantum yields and lifetimes for $\left[\mathrm{Dy}_{2 x} \mathrm{Eu}_{2-2 x}(\mathrm{bdc})_{3^{-}}\right.$ $\left.\left(\mathrm{H}_{2} \mathrm{O}\right)_{4}\right]_{\infty}$.

\begin{tabular}{lllll}
\hline Compound & $\begin{array}{l}\mathrm{Eu}^{3+} \\
\tau_{\text {obs }} \\
(\mu \mathrm{s})\end{array}$ & $\begin{array}{l}Q_{\mathrm{Eu}}^{\text {ligand }} \\
(\%)\end{array}$ & $\begin{array}{l}\mathrm{Dy}^{3+} \\
\tau_{\text {obs }} \\
(\mu \mathrm{s})\end{array}$ & $\begin{array}{l}Q_{\mathrm{Dy}}^{\text {ligand }} \\
(\%)\end{array}$ \\
\hline$\left[\mathrm{Eu}_{2}(\mathrm{bdc})_{3}\left(\mathrm{H}_{2} \mathrm{O}\right)_{4}\right]_{\infty}$ & $420(4)$ & $13.9(1)$ & - & - \\
{$\left[\mathrm{Dy}_{0.25} \mathrm{Eu}_{1.75}(\mathrm{bdc})_{3}\left(\mathrm{H}_{2} \mathrm{O}\right)_{4}\right]_{\infty}$} & $139(14)$ & $4.5(1)$ & - & $0.07(1)$ \\
{$\left[\mathrm{Dy}_{0.50} \mathrm{Eu}_{1.50}(\mathrm{bdc})_{3}\left(\mathrm{H}_{2} \mathrm{O}\right)_{4}\right]_{\infty}$} & $93(10)$ & $3.3(1)$ & - & $0.09(1)$ \\
{$\left[\mathrm{Dy}_{1.00} \mathrm{Eu}_{1.00}(\mathrm{bdc})_{3}\left(\mathrm{H}_{2} \mathrm{O}\right)_{4}\right]_{\infty}$} & $51(5)$ & $1.4(1)$ & - & $0.10(1)$ \\
{$\left[\mathrm{Dy}_{1.50} \mathrm{Eu}_{0.50}(\mathrm{bdc})_{3}\left(\mathrm{H}_{2} \mathrm{O}\right)_{4}\right]_{\infty}$} & $37(4)$ & $0.8(1)$ & - & $0.12(1)$ \\
{$\left[\mathrm{Dy}_{1.75} \mathrm{Eu}_{0.25}(\mathrm{bdc})_{3}\left(\mathrm{H}_{2} \mathrm{O}\right)_{4}\right]_{\infty}$} & $29(3)$ & $0.5(1)$ & - & $0.12(1)$ \\
{$\left[\mathrm{Dy}_{1.90} \mathrm{Eu}_{0.10}(\mathrm{bdc})_{3}\left(\mathrm{H}_{2} \mathrm{O}\right)_{4}\right]_{\infty}$} & $24(3)$ & $0.5(1)$ & - & $0.15(1)$ \\
{$\left[\mathrm{Dy}_{2}(\mathrm{bdc})_{3}\left(\mathrm{H}_{2} \mathrm{O}\right)_{4}\right]_{\infty}$} & - & - & $1.1(1)$ & $0.28(3)$
\end{tabular}

The overall quantum yields and the lifetimes for both the $\mathrm{Eu}^{3+}$ and $\mathrm{Dy}^{3+}$ ions decrease abruptly as soon as the material contains some of the other ion. This suggests that there is a reciprocal energy transfer Eu-to-Dy and Dy-to-Eu between these two ions. However, the decrease is more pronounced for the $\mathrm{Eu}^{3+}$ ions. This could be related to the fact that intermetallic deactivation is more efficient for the $\mathrm{Dy}^{3+}$ ions than for the $\mathrm{Eu}^{3+}$ ions, as suggested before.

The same study was realized for some compounds with the general chemical formula $\left[\mathrm{Dy}_{2 x} \mathrm{~Tb}_{2-2 x}(\mathrm{bdc})_{3}\left(\mathrm{H}_{2} \mathrm{O}\right)_{4}\right]_{\infty}$ (see Table 9). The results are quite similar and again reveal an efficient reciprocal energy transfer between the $\mathrm{Dy}^{3+}$ and $\mathrm{Tb}^{3+}$ ions.

Table 9. Quantum yields and lifetimes for $\left[\mathrm{Dy}_{2 x} \mathrm{~Tb}_{2-2 x}(\mathrm{bdc})_{3^{-}}\right.$ $\left.\left(\mathrm{H}_{2} \mathrm{O}\right)_{4}\right]_{\infty}$

\begin{tabular}{lllll}
\hline Compound & $\begin{array}{l}\mathrm{Tb}^{3+} \\
\tau_{\text {obs }} \\
(\mathrm{ms})\end{array}$ & $\begin{array}{l}Q_{\mathrm{Tb}}^{\text {ligand }} \\
(\%)\end{array}$ & $\begin{array}{l}\mathrm{Dy}^{3+} \\
\tau_{\text {obs }} \\
(\mu \mathrm{s})\end{array}$ & $\begin{array}{l}Q_{\mathrm{Dy}}^{\text {ligand }} \\
(\%)\end{array}$ \\
\hline$\left[\mathrm{Tb}_{2}(\mathrm{bdc})_{3}\left(\mathrm{H}_{2} \mathrm{O}\right)_{4}\right]_{\infty}$ & $1.10(1)$ & $45.5(45)$ & - & - \\
{$\left[\mathrm{Dy}_{0.50} \mathrm{~Tb}_{1.50}(\mathrm{bdc})_{3}\left(\mathrm{H}_{2} \mathrm{O}\right)_{4}\right]_{\infty}$} & $0.42(1)$ & $1.6(2)$ & $2.4(2)$ & $0.07(1)$ \\
{$\left[\mathrm{Dy}_{1.00} \mathrm{Eu}_{1.00}(\mathrm{bdc})_{3}\left(\mathrm{H}_{2} \mathrm{O}\right)_{4}\right]_{\infty}$} & $0.22(1)$ & $0.5(1)$ & $1.9(1)$ & $0.05(1)$ \\
{$\left[\mathrm{Dy}_{1.50} \mathrm{Eu}_{0.50}(\mathrm{bdc})_{3}\left(\mathrm{H}_{2} \mathrm{O}\right)_{4}\right]_{\infty}$} & $0.12(1)$ & $0.1(1)$ & $1.5(1)$ & $0.03(2)$ \\
{$\left[\mathrm{Dy}_{2}(\mathrm{bdc})_{3}\left(\mathrm{H}_{2} \mathrm{O}\right)_{4}\right]_{\infty}$} & - & - & $1.1(1)$ & $0.28(1)$ \\
\hline
\end{tabular}




\section{Conclusions}

We have reported here on a family of heterobimetallic and heterotrimetallic lanthanide-based coordination polymers in which brightness and color are tunable: (1) The best brightness was obtained for $20 \%$ doping in either $\mathrm{Tb}^{3+}$ - or $\mathrm{Eu}^{3+}$-containing compounds. (2) The best color modulation was obtained for $0.7 \leq x \leq 1$ in the $\left[\mathrm{Eu}_{2-2 x} \mathrm{~Tb}_{2 x}(\mathrm{bdc})_{3^{-}}\right.$ $\left.\left(\mathrm{H}_{2} \mathrm{O}\right)_{4}\right]_{\infty}$ series. (3) The combined approach can be conducted by using heterotrinuclear coordination polymers. To the best of our knowledge, this series is the most extended one that has been reported to date. Thanks to great chemical and thermal stabilities and unique optical properties, the compounds that belong to this family are interesting from a practical point of view. For instance, they are luminescent under $312 \mathrm{~nm}$ UV irradiation, which is a cheap commercially available wavelength; their emission brightness can be tuned by optical dilution; and their emission color can be adjusted by modifying the composition of the polymetallic derivatives.

This study also shed light on nonradiative and energymigration intermetallic processes, which are very efficient and must be as controlled as possible. This was illustrated by the heteropolymetallic coordination polymer containing three luminescent lanthanide ions $\left(\mathrm{Tb}^{3+}, \mathrm{Eu}^{3+}\right.$, and $\left.\mathrm{Dy}^{3+}\right)$ in which an optically inactive low-costing lanthanide ion $\left(\mathrm{La}^{3+}\right)$ played the role of dilutant to minimize intermetallic deactivation. This compound with the chemical formula $\left[\mathrm{La}_{1.600} \mathrm{Dy}_{0.352} \mathrm{~Tb}_{0.040} \mathrm{Eu}_{0.008}(\mathrm{bdc})_{3}\left(\mathrm{H}_{2} \mathrm{O}\right)_{4}\right]_{\infty}$ exhibits pale yellow luminescence under UV irradiation (Figure 16). Colorimetric measurements indicate that this luminescence is almost white $(x=0.40, y=0.42)$.

The composition of this compound is not yet fully optimized, but our group is currently working towards this goal.

\section{Experimental Section}

Synthesis of the Microcrystalline Powders: Terephthalic acid and lanthanide oxides were purchased from Acros Organics and Strem Chemicals, respectively. They were used without further purification. Disodium terephthalate was prepared as described elsewhere. ${ }^{[31]}$ Hydrated lanthanide chlorides were prepared from the corresponding oxides according to literature methods. ${ }^{[54]}$ Microcrystalline powders of the coordination polymers were obtained as described previously. ${ }^{[31]}$ The obtained microcrystalline powders were all assumed to be isostructural to the structurally described $\left[\mathrm{Tb}_{2}(\mathrm{bdc})_{3}\left(\mathrm{H}_{2} \mathrm{O}\right)_{4}\right]_{\infty}$ compound ${ }^{[25]}$ on the basis of their X-ray powder diffraction diagrams (Figures S4-S10, Supporting Information). The granulometry of the microcrystalline powders was measured by using a Cilas Laser Size 1180. All of the measured powders display similar size distribution: $25 \%$ of the particles had a size $<0.3 \mu \mathrm{m}, 50 \%$ had a size between 0.3 and $1.4 \mu \mathrm{m}$, and the size of the remaining $25 \%$ ranged between 1.4 and $9.0 \mu \mathrm{m}$. There was also a great amount of particles around $50 \mathrm{~nm}$ in size, which can be related to the size of the elemental crystallites that constitute the particles. This is in perfect agreement with that observed for the related mononuclear compounds. ${ }^{[26]}$ The chemical homogeneity of the powders was checked by SEM measurements. The results were in good agreement with each other as well as with that anticipated during synthesis. They confirm that all the particles that form the microcrystalline powders had the same chemical formula as the powders themselves. The monophasic character of the microcrystalline powders was checked by X-ray diffraction. This study also revealed that there was no long-range order or segregation in these compounds and that in the heterometallic compounds the metallic ions were randomly distributed on the metallic sites of the crystal structure. $^{[31]}$

Solid-State Luminescence Measurements: Solid-state emission spectra were measured with a Horiba Jobin-Yvon Fluorolog III fluorescence spectrometer with a pulsed Xe lamp. Slit widths for excitation and emission were $2 \mathrm{~nm}$ for the Eu- and Tb-containing compounds and $5 \mathrm{~nm}$ for the Sm- and Dy-containing compounds. Luminescence spectra were all recorded at room temperature between
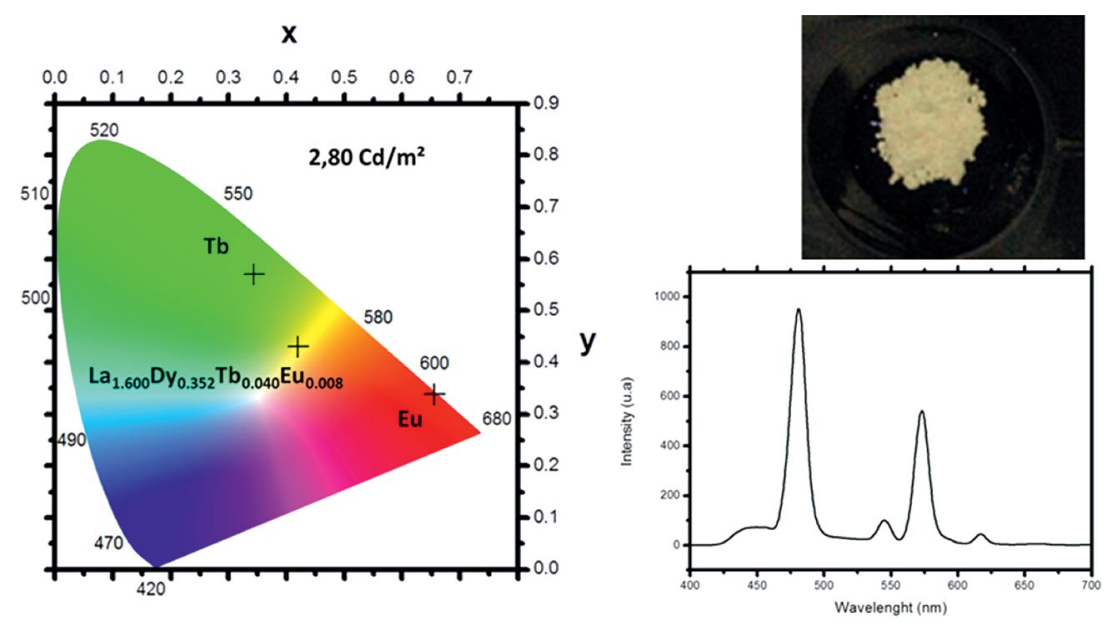

Figure 16. Colorimetric and spectroscopic data for $\left[\mathrm{La}_{1.600} \mathrm{Dy}_{0.352} \mathrm{~Tb}_{0.040} \mathrm{Eu}_{0.008}(\mathrm{bdc})_{3}\left(\mathrm{H}_{2} \mathrm{O}\right)_{4}\right]_{\infty}$. Top right: A picture of the microcrystalline powder under UV irradiation $\left(\lambda_{\mathrm{exc}}=312 \mathrm{~nm}\right)$. 
450 and $800 \mathrm{~nm}$. The data were collected at every nanometer with an integration time of $100 \mathrm{~ms}$ for each step. The quantum yield measurements were performed by using a Jobin-Yvon integrating sphere $\left[\Phi=\left(E_{\mathrm{c}}-E_{\mathrm{a}}\right) /\left(L_{\mathrm{a}}-L_{\mathrm{c}}\right)\right.$ in which $E_{\mathrm{c}}$ is the integrated emission spectrum of the sample, $E_{\mathrm{a}}$ is the integrated "blank" emission spectrum, $L_{\mathrm{a}}$ is the "blank" absorption, and $L_{\mathrm{c}}$ is the sample absorption at the excitation wavelength]. Comparative solid-state luminescence spectra were measured with a Perkin-Elmer LS-55 spectrometer between 450 and $800 \mathrm{~nm}$ under identical operating conditions and without turning the lamp off to ensure a valid comparison between the emission spectra. Reproducibility of the measurements as well as surface states of the samples were carefully checked. Slit widths for excitation and emission were 5 or $10 \mathrm{~nm}$ depending on the series of samples. The solid-state luminescence spectrum of the Gd-containing compound was recorded at $77 \mathrm{~K}$ to obtain the energy level of the lowest ligand triplet state (see Figure S11, Supporting Information). Luminescence intensities of the samples expressed in $\mathrm{Cd} \mathrm{m}^{-2}$ were measured with a Gigahertz-Optik X1-1 optometer with an integration time of $200 \mathrm{~ms}$ on $1.5 \mathrm{~cm}^{2}$ pellets. The intensity of the UV flux, $2.5(1) \mathrm{Wm}^{-2}$, was measured with a Vilber Lourmat VLX-3 W radiometer.

UV/Vis Absorption Measurements: The UV/Vis absorption spectra were recorded with a Perkin-Elmer Lambda 650 spectrometer. Solid-state measurements were recorded by using a praying mantis unit. The solid-state UV/Vis absorption spectrum of the Tb-containing compound was recorded for estimating the energy of the lowest singlet excited state of the ligand (see Figure S12, Supporting Information). Liquid-state measurements were performed to evaluate the molar absorption coefficients of the bdc ${ }^{2-}$ ligands (see Figure S2, Supporting Information).

Colorimetric Measurements: The CIE (Commission Internationale de l'éclairage) $(x, y)$ emission color coordinates ${ }^{[5]}$ were obtained by using a MSU-003 colorimeter (Majantys) with the PhotonProbe 1.6.0 Software (Majantys). The excitation wavelength was $312 \mathrm{~nm}$. As references, the emission color coordinates of the standard red $\mathrm{Gd}_{2} \mathrm{O}_{2} \mathrm{~S}: \mathrm{Eu}(x=0.667, y=0.330)$ and green $\mathrm{Gd}_{2} \mathrm{O}_{2} \mathrm{~S}: \mathrm{Tb}(x=$ $0.328, y=0.537$ ) phosphors from Phosphor Technology were measured. Color measurements: $2^{\circ}$, CIE 1931, step $5 \mathrm{~nm}$, under $312 \mathrm{~nm}$ UV light.

$$
\begin{aligned}
& \mathrm{X}=\mathrm{k} \times \int_{380 \mathrm{~nm}}^{780 \mathrm{~mm}} \mathrm{I}_{\lambda} \times \mathrm{x}_{\lambda} \\
& \mathrm{Y}=\mathrm{k} \times \int_{380 \mathrm{~nm}}^{780 \mathrm{~mm}} \mathrm{I}_{\lambda} \times \mathrm{y}_{\lambda} \\
& \mathrm{Z}=\mathrm{k} \times \int_{380 \mathrm{~nm}}^{780 \mathrm{~mm}} \mathrm{I}_{\lambda} \times \mathrm{z}_{\lambda}
\end{aligned}
$$

in which $k$ was held constant for the measurement system; $I_{\lambda}$ is the sample spectrum intensity wavelength; and $x_{\lambda}, y_{\lambda}$, and $z_{\lambda}$ are the trichromatic values $x=X /(X+Y+Z), y=Y /(X+Y+Z)$, and $z$ $=Z /(X+Y+Z)$. Mean $x, y$, and $z$ values are given for each sample, which acts as a light source (luminescent sample).

Solid-State ${ }^{89} \mathbf{Y}$ NMR Measurements: Solid-state NMR spectra were acquired by using a Bruker Avance III spectrometer equipped with a $14.1 \mathrm{~T}$ magnet at Larmor frequencies of $150.9 \mathrm{MHz}$ for ${ }^{13} \mathrm{C}$ and $29.4 \mathrm{MHz}$ for ${ }^{89} \mathrm{Y}$. Samples were packed into $4 \mathrm{~mm}$ outer diameter rotors and rotated at rates between 12.5 and $14 \mathrm{kHz}$ by using a commercial HX or HX "low- $\gamma$ " probehead. ${ }^{13} \mathrm{C}$ MAS NMR spectra were acquired by using cross polarization (CP) from ${ }^{1} \mathrm{H}$ by using a contact pulse duration of $1 \mathrm{~ms}$ (ramped $90-100 \%$ for ${ }^{1} \mathrm{H}$ ), and two-pulse phase modulation (TPPM) ${ }^{1} \mathrm{H}$ decoupling during acquisition with an radio frequency field strength of $\approx 80 \mathrm{kHz}$. Spectra are the result of averaging 1200 transients with a recycle interval of $3 \mathrm{~s} .{ }^{89} \mathrm{Y}$ MAS NMR spectra were acquired with a radio frequency field strength of $22 \mathrm{kHz}$ by using a short $(\pi / 6)$ flip angle.
Preacquisition intervals of $\approx 80 \mu$ s were used to eliminate problems resulting from probe ringdown. Spectra are the result of averaging between 280 and 328 transients with a recycle interval of $300 \mathrm{~s}$. The background signal arising from the rotor occurs outside of the spectral range shown. Chemical shift scales are shown relative to TMS for ${ }^{13} \mathrm{C}$ and $1 \mathrm{M} \mathrm{YCl}_{3}$ (aq.), the latter measured by using $\mathrm{Y}_{2} \mathrm{Ti}_{2} \mathrm{O}_{7}$ as a secondary reference $(\delta=65 \mathrm{ppm})$.

Supporting Information (see footnote on the first page of this article): Solid-state excitation spectrum for $\left[\mathrm{Tb}_{2}(\mathrm{bdc})_{3}\left(\mathrm{H}_{2} \mathrm{O}\right)_{4}\right]_{\infty}$, absorbance versus concentration of aqueous solution of sodium terephthalate, colorimetric coordinates for $\left[\mathrm{La}_{2 x} \mathrm{~Tb}_{2-2 x}(\mathrm{bdc})_{3^{-}}\right.$ $\left.\left(\mathrm{H}_{2} \mathrm{O}\right)_{4}\right]_{\infty}$ compounds, XRD diagrams for some of the studied compounds, solid-state emission spectrum of $\left[\mathrm{Gd}_{2}(\mathrm{bdc})_{3}\left(\mathrm{H}_{2} \mathrm{O}\right)_{4}\right]_{\infty}$ recorded at $77 \mathrm{~K}$, solid-state absorption spectra, and colorimetric data for $\left[\mathrm{Tb}_{2 x} \mathrm{Eu}_{2-2 x}(\mathrm{bdc})_{3}\left(\mathrm{H}_{2} \mathrm{O}\right)_{4}\right]_{\infty}$.

\section{Acknowledgments}

Région Bretagne is acknowledged for financial support (LUMINMAT program). J. C. B. thanks the World Class University Program funded by the Ministry of Education, Science, and Technology through the National Science Foundation of Korea (grant R312012-000-10035-0) for support. S. E. thanks the French National Research Agency (Project ANR-10-BLAN-1513). This research received financial support from Fonds Européen de Développement Régional (FEDER) (FEDER 34722 - Prin ${ }^{2}$ Tan).

[1] O. M. Yaghi, G. Li, H. Li, Nature 1995, 378, 703.

[2] O. M. Yaghi, H. L. Li, J. Am. Chem. Soc. 1995, 117, 10401.

[3] M. Eddaoudi, J. Kim, N. Rosi, D. Vodak, J. Wachter, M. O'Keeffe, O. M. Yaghi, Science 2002, 295, 469.

[4] G. Férey, C. Serre, C. Mellot-Draznieks, F. Millange, S. Surblé, J. Dutour, I. Margiolaki, Angew. Chem. 2004, 116, 6456; Angew. Chem. Int. Ed. 2004, 43, 6296.

[5] G. Férey, C. Mellot-Draznieks, C. Serre, F. Millange, Acc. Chem. Res. 2004, 37, 217.

[6] D. Kustaryono, N. Kerbellec, G. Calvez, C. Daiguebonne, O. Guillou, Cryst. Growth Des. 2010, 10, 775.

[7] Y. Luo, G. Calvez, S. Freslon, C. Daiguebonne, T. Roisnel, O. Guillou, Inorg. Chim. Acta 2010, 368, 170.

[8] F. A. Almeida Paz, J. Klinowski, S. M. F. Vilela, J. P. C. Tome, J. A. S. Cavaleiro, J. Rocha, Chem. Soc. Rev. 2012, 41, 1088.

[9] J. Lee, O. K. Farha, J. Roberts, A. Scheidts, S. T. Nguyen, J. T. Hupp, Chem. Soc. Rev. 2009, 38, 1450.

[10] L. Hamon, P. L. Llewellyn, T. Devic, A. Ghoufi, G. Clet, V. Guillerm, G. D. Pirngruber, G. Maurin, C. Serre, G. Driver, W. van Beek, E. Jolimaitre, A. Vimont, M. Daturi, G. Férey, J. Am. Chem. Soc. 2009, 131, 17490.

[11] A. J. Lan, K. H. Li, H. H. Wu, D. H. Olson, T. J. Emge, W. Ki, M. C. Hong, J. Li, Angew. Chem. 2009, 121, 2370; Angew. Chem. Int. Ed. 2009, 48, 2334.

[12] Y. Luo, G. Calvez, S. Freslon, K. Bernot, C. Daiguebonne, O. Guillou, Eur. J. Inorg. Chem. 2011, 3705.

[13] J. Feng, H. J. Zhang, Chem. Soc. Rev. 2013, 42, 387.

[14] Y. Cui, Y. Yue, G. Qian, B. Chen, Chem. Rev. 2012, 112, 126.

[15] Y. Cui, H. Xu, Y. Yue, Z. Guo, J. Yu, Z. Chen, J. Gao, Y. Yang, G. Qian, B. Chen, J. Am. Chem. Soc. 2012, 134, 3979.

[16] J. C. G. Bünzli, S. V. Eliseeva, Chem. Science 2013, 4, 1939 1949.

[17] K. Bernot, J. Luzon, A. Caneschi, D. Gatteschi, R. Sessoli, L. Bogani, A. Vindigni, A. Rettori, M. G. Pini, Phys. Rev. B 2009, $79,134419$.

[18] G. Calvez, K. Bernot, O. Guillou, C. Daiguebonne, A. Caneschi, N. Mahé, Inorg. Chim. Acta 2008, 361, 3997.

[19] J. R. Jeon, R. Clérac, Dalton Trans. 2012, 41, 9569.

[20] R. G. Pearson, Coord. Chem. Rev. 1990, 403. 
[21] R. G. Pearson, J. Am. Chem. Soc. 1963, 85, 3533.

[22] Y. Qiu, C. Daiguebonne, J. Liu, R. Zeng, N. Kerbellec, H. Deng, O. Guillou, Inorg. Chim. Acta 2007, 360, 3265.

[23] K. Binnemans, Chem. Rev. 2009, 109, 4283.

[24] O. Guillou, C. Daiguebonne in Handbook on the Physics and Chemistry of Rare Earths (Eds.: K. A. Gschneider, J. C. G. Bünzli, V. K. Pecharsky), Elsevier, Amsterdam, 2005, vol. 34, p. 359.

[25] T. M. Reneike, M. Eddaoudi, M. Fehr, D. Kelley, O. M. Yaghi, J. Am. Chem. Soc. 1999, 121, 1651.

[26] C. Daiguebonne, N. Kerbellec, O. Guillou, J. C. G. Bünzli, F. Gumy, L. Catala, T. Mallah, N. Audebrand, Y. Gérault, K. Bernot, G. Calvez, Inorg. Chem. 2008, 47, 3700.

[27] N. Kerbellec, L. Catala, C. Daiguebonne, A. Gloter, O. Stephan, J. C. G. Bünzli, O. Guillou, T. Mallah, New J. Chem. 2008, 32, 584 .

[28] C. Daiguebonne, N. Kerbellec, K. Bernot, Y. Gérault, A. Deluzet, O. Guillou, Inorg. Chem. 2006, 45, 5399.

[29] Z. Wang, Y. Yang, Y. Cui, Z. Wang, G. Qian, J. Alloys Compd. 2012, 510, L5.

[30] R. Decadt, K. Van Hecke, D. Depla, K. Leus, D. Weidenberg, I. Van Driessche, P. Van der Voort, R. Van Deun, Inorg. Chem. 2012, 51, 11623.

[31] N. Kerbellec, D. Kustaryono, V. Haquin, M. Etienne, C. Daiguebonne, O. Guillou, Inorg. Chem. 2009, 48, 2837.

[32] V. Haquin, F. Gumy, C. Daiguebonne, J. C. G. Bünzli, O. Guillou, Eur. J. Inorg. Chem. 2009, 491.

[33] C. Daiguebonne, O. Guillou, N. Kerbellec, INSA: European Patent, PCT/EP2008/056904, 2008

[34] C. Daiguebonne, O. Guillou, N. Kerbellec, INSA: French Patent FR2906393, 2008.

[35] D. T. De Lill, A. De Bettencourt-Dias, C. L. Cahill, Inorg. Chem. 2007, 46, 3960.

[36] M. O. Rodrigues, J. D. L. Dutra, L. A. O. Nunes, G. F. de Sá, W. M. de Azevedo, P. Silva, F. A. A. Paz, R. O. Freire, S. A. Júnior, J. Phys. Chem. C 2012, 116, 19951.

[37] S. Dang, J. H. Zhang, Z. M. Sun, J. Mater. Chem. 2012, 22, 8868.

[38] M. R. Mitchell, D. Carnevale, R. Orr, K. R. Whittle, S. E. Ashbrook, J. Phys. Chem. C 2012, 116, 4273.

[39] S. W. Reader, M. R. Mitchell, K. E. Johnston, C. J. Pickard, K. R. Whittle, S. E. Ashbrook, J. Phys. Chem. C 2009, 113, 18874.
[40] S. E. Ashbrook, K. R. Whittle, G. R. Lumpkin, I. Farnan, J. Phys. Chem. B 2006, 110, 10358.

[41] J. Roger, V. Babizhetsky, S. Cordier, J. Bauer, K. Hiebl, L. Le Pollès, S. E. Ashbrook, J. F. Halet, R. Guérin, J. Solid State Chem. 2005, 178, 1851.

[42] Y. Luo, Y. Zheng, G. Calvez, S. Freslon, K. Bernot, C. Daiguebonne, T. Roisnel, O. Guillou, CrystEngComm 2013, 15, 706.

[43] S. V. Eliseeva, J. C. G. Bünzli, Chem. Soc. Rev. 2010, 39, 189.

[44] M. Shi, F. Li, T. Yi, D. Zhang, H. Hu, C.-H. Huang, Inorg. Chem. 2005, 44, 8929.

[45] L. Prodi, M. Maestri, R. Ziessel, V. Balzani, Inorg. Chem. 1991, 30, 3798

[46] S. Quici, M. Cavazzini, G. Marzanni, G. Accorsi, N. Armaroli, B. Ventura, F. Barigelletti, Inorg. Chem. 2005, 44, 529.

[47] F. J. Steemers, W. Verboom, D. N. Reinhoudt, E. B. Van der Tol, J. W. Verhoeven, J. Am. Chem. Soc. 1995, 117, 9408.

[48] M. Latva, H. Takalo, V.-M. Mukkala, C. Matachescu, J. C. Rodriguez-Ubis, J. Kankare, J. Lumin. 1997, 75, 149.

[49] J.-C. G. Bünzli, S. Comby, A.-S. Chauvin, C. D. B. Vandevyver, J. Rare Earths 2007, 25, 257.

[50] A. S. Chauvin, F. Gumy, D. Imbert, J. C. G. Bünzli, Spectrosc. Lett. 2004, 37, 512 .

[51] S. V. Eliseeva, D. N. Pleshkov, K. A. Lyssenko, L. S. Lepnev, J. C. G. Bünzli, N. P. Kuzmina, Inorg. Chem. 2010, 49, 9300.

[52] D. L. Dexter, J. Chem. Phys. 1953, 21, 836.

[53] T. Förster, Comparative Effects of Radiation, John Wiley \& Sons, New York, 1960.

[54] J. F. Desreux in Lanthanide Probes in Life, Chemical and Earth Sciences (Eds.: G. R. Choppin, J. C. G. Bünzli), Elsevier, Amsterdam, 1989, p. 43.

[55] G. Wyszecki in Handbook of Optics (Eds.: W. G. Driscoll, W. Vaughan), McGraw-Hill Book Company, New York, 1978, p. $1-15$.

[56] The summation symbol is used here for simplifying the writing of the general chemical formula. It means that the compounds can contain between 1 and 13 different lanthanide ions, all the relative proportions being accessible.

Received: March 20, 2013 Published Online: June 7, 2013 